\title{
MUREX: a land-surface field experiment to study the annual cycle of the energy and water budgets
}

\author{
J.-C. Calvet ${ }^{1}$, P. Bessemoulin ${ }^{1}$, J. Noilhan ${ }^{1}$, C. Berne ${ }^{1}$, I. Braud ${ }^{2}$, D. Courault ${ }^{3}$, N. Fritz ${ }^{1}$, E. Gonzalez-Sosa ${ }^{2}$, \\ J.-P. Goutorbe ${ }^{1}$, R. Haverkamp ${ }^{2}$, G. Jaubert ${ }^{1}$, L. Kergoat ${ }^{4}$, G. Lachaud ${ }^{1}$, J.-P. Laurent ${ }^{2}$, P. Mordelet ${ }^{5}$, \\ A. Olioso ${ }^{3}$, P. Péris ${ }^{1}$, J.-L. Roujean ${ }^{1}$, J.-L. Thony ${ }^{2}$, C. Tosca $^{5}$, M. Vauclin ${ }^{2}$, D. Vignes ${ }^{5}$ \\ ${ }^{1}$ Météo-France, CNRM/GAME, URA CNRS 1357, 31057 Toulouse Cedex 1, France \\ 2 LTHE, UMR CNRS 5564, INPG, ORSTOM, UJF, BP53 38041 Grenoble Cedex 9, France \\ ${ }^{3}$ INRA Bioclimatologie, 84914 Avignon Cedex 9, France \\ ${ }^{4}$ Laboratoire d'Ecologie Terrestre, UMR CNRS 5552, 31405 Toulouse Cedex 4, France \\ ${ }^{5}$ CESBIO, UMR CNRS 141, 31401 Toulouse Cedex 4, France
}

Received: 9 September 1998 / Revised: 25 February 1999 / Accepted: 26 February 1999

\begin{abstract}
The MUREX (monitoring the usable soil reservoir experimentally) experiment was designed to provide continuous time series of field data over a long period, in order to improve and validate the Soilvegetation-Atmosphere Transfer (SVAT) parameterisations employed in meteorological models. Intensive measurements were performed for more than three years over fallow farmland in southwestern France. To capture the main processes controlling land-atmosphere exchanges, the local climate was fully characterised, and surface water and energy fluxes, vegetation biomass, soil moisture profiles, surface soil moisture and surface and soil temperature were monitored. Additional physiological measurements were carried out during selected periods to describe the biological control of the fluxes. The MUREX data of 1995, 1996, and 1997 are presented. Four SVAT models are applied to the annual cycle of 1995. In general, they succeed in simulating the main features of the fallow functioning, although some shortcomings are revealed.
\end{abstract}

Key words. Hydrology (evapotranspiration; soil moisture; water-energy interactions).

\section{Introduction}

The MUREX (monitoring the usable soil reservoir experimentally) experiment (Bessemoulin et al., 1996; Calvet et al., 1998a) was initiated in 1994. At that time, a number of large-scale field experiments focused on land surface-atmosphere interactions had already been

Correspondence to: J.-C. Calvet

Météo-France/CNRM, 42 Av. Coriolis, 31057

Toulouse Cedex 1, France

E-mail: jean-christophe.calvet@meteo.fr carried out, e.g. HAPEX-MOBILHY (André et al., 1986), FIFE (Sellers et al., 1992), EFEDA (Bolle et al., 1993), and HAPEX-Sahel (Goutorbe et al., 1997). These campaigns allowed successful calibration and validation of several soil-vegetation-atmosphere transfer models (hereafter denoted as SVATs), e.g. the ISBA (interaction between soil, biosphere, and atmosphere) scheme developed by Noilhan and Planton (1989) suitable for coupling with meteorological or climate models, or the detailed SiSPAT scheme (simple soil-plant-atmosphere transfer model) designed by Braud et al. (1995). The development and implementation of SVATs in general circulation models (GCM) or climate models clearly demonstrated the positive impact of good representations of vegetation in atmospheric models, particularly its ability to modify turbulent and radiative exchanges, and to modulate the extraction of soil water.

However, the limited duration of such campaigns (no more than two months for most intensive field campaigns) prevented testing the model's ability to reproduce the annual or inter-annual water cycle, for which longer validation datasets are required. The motivation for a long-term field documentation of relevant processes was confirmed by the Project for Intercomparison of Land Surface Parametrisation Schemes (PILPS). In PILPS phase II (Chen et al., 1997), 23 schemes were run to compare the various predicted components of the energy balance with experimental data collected over a meadow at Cabauw, the Netherlands. It was found that even for this relatively simple type of surface, significant differences occurred between models and observations, and models themselves. For example, the modelled annual mean evaporation ranged between $32 \mathrm{~W} \mathrm{~m}^{-2}$ (about $400 \mathrm{~mm} \mathrm{y}^{-1}$ ) and $56 \mathrm{Wm}^{-2}$ (about $710 \mathrm{~mm} \mathrm{y}^{-1}$ ), while the measured value was $42 \mathrm{Wm}^{-2}\left(530 \mathrm{~mm} \mathrm{y}^{-1}\right)$. Such large errors of energy flux estimates in atmospheric models may have a powerful impact on predicted soil moisture and surface runoff, with a possible feedback on cloud amount and precipitations. Koster and Milly (1997) showed that the large scatter in PILPS flux calculations was related to the modelling of the interplay 
between transpiration and runoff. However, it was not possible to propose better parametrisations based on the PILPS datasets because all the key SVAT variables (i.e. soil moisture, surface fluxes, and leaf area index, $L A I$ ) were not measured at the same time during long enough periods.

Based on this result, it was concluded that there was real need for testing land-surface schemes against measurements of all the components of the energy and hydrological budgets, the seasonal variation of vegetation properties and soil moisture, and the variation of the atmospheric forcing, during at least three annual cycles. An additional motivation for undertaking such a program was that some components of the hydrological budget, such as runoff or gravitational drainage, essential for understanding hydrologic systems, are only accessible from long-term measurements (annual or seasonal cycles).

The resulting MUREX field experiment presented is a joint effort of Météo-France/CNRM (Centre National de Recherches Météorologiques, Toulouse, France), CESBIO (Centre d'Etudes Spatiales de la Biosphère, Toulouse, France) and LTHE (Laboratoire d'Etude des Transferts en Hydrologie et Environnement, Grenoble, France). The site is described and a summary of the database is presented over three annual cycles (1995 to 1997). Finally, different modelling approaches are applied to the data of 1995 .

\section{Main characteristics of the site}

The difficulties in maintaining numerous automatic measurements for a long period and in conducting frequent investigations of the soil and vegetation at an isolated site lead to the choice of a site close to CNRM, $30 \mathrm{~km}$ away from the city of Toulouse (France). Since the aim of MUREX is to characterise the natural interactions between surface fluxes, soil water content, and vegetation functionning, it was intended to:
(1) avoid any influence of river water tables on the water budget and (2) search for a natural canopy whose characteristics do not change fundamentally from one year to another. Since river water tables are often close to the surface in valleys, the Toulouse region offers a limited choice of sites satisfying this requirement. It was thus decided to select a fallow site over one of the plateaux dominating the main watersheds of the region.

The MUREX fallow site $\left(43^{\circ} 24^{\prime} \mathrm{N} ; 1^{\circ} 10^{\prime} \mathrm{E}\right.$; altitude: $240 \mathrm{~m}$ ) was an agricultural area abandoned in 1992. The micrometeorological station (Fig. 1) was set up in June 1994. The field was large enough (about 700 by $250 \mathrm{~m}$ ) to provide a good fetch. It was a rather flat parcel, gently sloping down to the edge of a plateau dominating the valley of the Touch river, $30 \mathrm{~m}$ below. The vegetation canopy of the MUREX site consisted of a dense herbaceous agricultural fallow. The main plant species were: Brachypodium sp and Potentilla reptans, especially, and also Geranium rotundifolium, Erigeron canadensis, and Rumex acetosa, as observed on day of year (DoY) 293 in 1995. The canopy height ranged from $1 \mathrm{~m}$ when vegetation was fully developed, to $0.1 \mathrm{~m}$ in winter. The soil was a typical hydromorphic deep 'boulbene': the mean texture of the $1 \mathrm{~m}$ surface soil layer was that of a silt-loam (the sand and clay fractions were 14 and 28\%, respectively). However, strong vertical texture gradients were observed: the proportion of clay increased from $17 \%$ at the surface to $40 \%$ at $1 \mathrm{~m}$ depth. On this type of soil, at about $1 \mathrm{~m}$, a local subsurface soil water convergence might sometimes occur, caused by a temporary perched water table over the clay bedrock.

The meteorological variables (precipitation, air temperature and humidity, wind speed and direction) at the site were monitored on a 30-min basis together with surface temperature, solar radiation, and the surface fluxes: net radiation $(R n)$, sensible heat flux $(H)$, ground heat flux $(G)$, and by difference the latent heat flux $L E=R n-H-G$. The other routine surface measurements consisted of weekly profiles of the deep soil

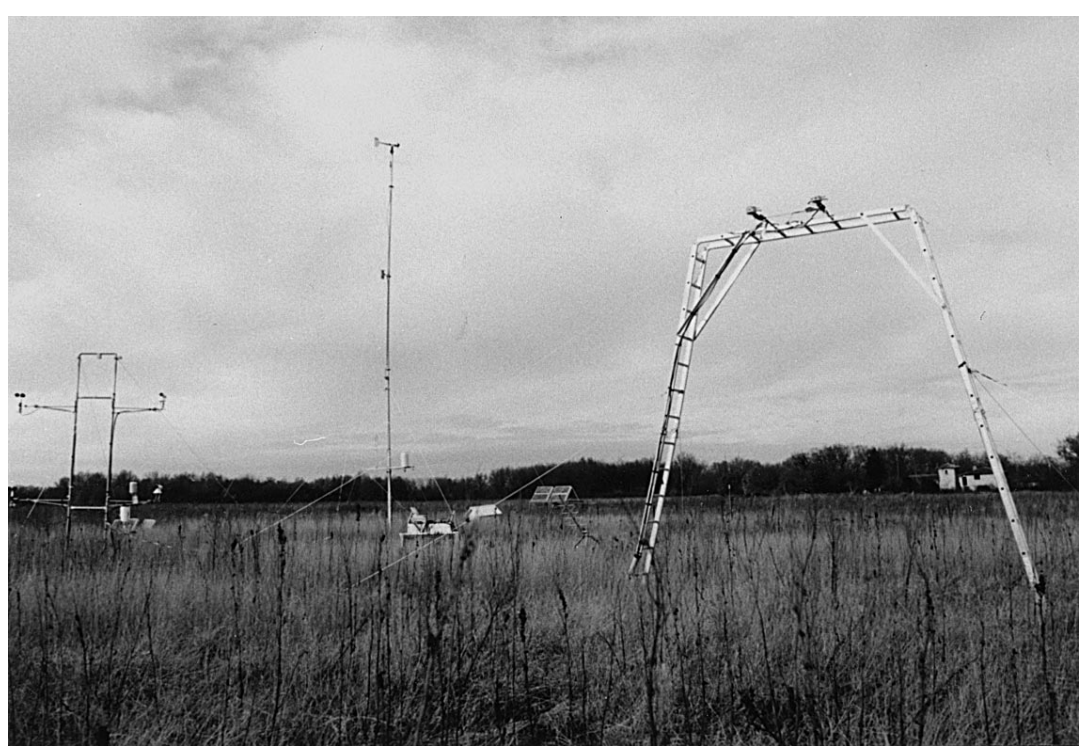

Fig. 1. Photograph of the central part of the MUREX fallow site (at the end of 1996) with some of the instrumentation. From left to right: the two-level SAMER system, the 10-m mast for wind, screen-level temperature and humidity, and IR-temperature, and the scaffolding bearing the radiation sensors 
moisture content, a characterisation of the vegetation, and 30-min recording of temperature profiles in the soil. Along with routine observations, more specific measurements were made during selected periods: (1) direct measurements of the soil moisture profile at the surface (the top $5 \mathrm{~cm}$ ) were performed during two 30-day intensive observing periods in spring and autumn 1995 (Calvet et al., 1998a); (2) the integrated surface soil moisture was routinely measured in 1997 by using automatic capacitive probes; (3) the surface temperature was derived from infrared radiometry from April to November of each annual cycle; (4) the $\mathrm{CO}_{2}$ fluxes were characterised from the summer 1997 to the spring of 1998; (5) the leaf stomatal conductance to water vapour was measured on selected days throughout the studied period, together with the leaf water potential; and (6) the soil hydraulic properties (hydraulic and thermal conductivities) were characterised. The latter measurements were particularly useful to run the SiSPAT model (see Sect. 6.3).

\section{Routine soil and atmospheric measurements}

The soil and atmospheric measurements of MUREX were obtained using methods very similar to those of HAPEX-MOBILHY (André et al., 1986): classical meteorological observations were combined with surface energy and water budget measurements.

\subsection{Atmospheric measurements}

The equipment employed was similar to the SAMER station described in Goutorbe (1991). Air temperature and humidity were measured at screen-level $(2 \mathrm{~m})$. The wind speed $(U)$ and direction were measured by a propeller anemometer at $10 \mathrm{~m}$ above the soil surface. The atmospheric pressure was measured and recorded automatically. The station was also able to document the surface energy balance: the net radiation was measured together with the ground heat flux, and the sensible heat was calculated from two-level measurements $(1.5 \mathrm{~m}$ apart) of air temperature and wind speed. The accuracy of the two-level measurements (air temperature and wind speed vertical gradients) was one order of magnitude better than the original design: the sensors were changed and thoroughly intercompared at the same level, under very distinct atmospheric conditions (i.e. different diurnal cycles, strong and low winds, rain/no rain, etc.). However, other uncertainties (e.g. concerning the canopy height estimation) may affect the obtained fluxes at short time scales, and the expected accuracy was about 20\% (Goutorbe, 1991).

Rainfall $(P)$ was recorded automatically using a tipping bucket rain gauge. Also, shortwave and total $(0.3-60 \mu \mathrm{m})$, upward and downward radiations were measured. The MUREX station was very reliable for the entire period studied. During 1995 for example less than $6 \%$ of surface flux data are missing, 1 to $3 \%$ of the radiation (the solar incident radiation $R g$ and the downwelling atmospheric thermal emission $R a$ ), pressure, and air temperature and humidity are missing, and less than $1 \%$ of wind speed and precipitation data are missing. In order to obtain a continuous atmospheric forcing series, data from neighbouring automatic weather stations (Poucharramet: $43^{\circ} 25^{\prime} \mathrm{N}, 1^{\circ} 11^{\prime} \mathrm{E}$, altitude $204 \mathrm{~m}$, and Ondes: $43^{\circ} 47^{\prime} \mathrm{N}, 1^{\circ} 19^{\prime} \mathrm{E}$, altitude $108 \mathrm{~m}$ ) and of the Francazal airport station $\left(43^{\circ} 32^{\prime} \mathrm{N}, 1^{\circ} 22^{\prime} \mathrm{E}\right.$, altitude $164 \mathrm{~m}$ ) were added to the database. Since the downwelling atmospheric thermal emission $(R a)$ was not measured in the supplementary weather stations, the $3 \%$ missing data in the original dataset were completed by the following formulation, adapted from Staley and Jurica (1972):

$$
\begin{aligned}
R a=\beta+\beta^{\prime} \times\{ & \sigma_{c}+\left(1-\sigma_{c}\right) \times 0.67 \\
& \left.\times\left(1670 \times q_{a}\right)^{0.08}\right\} \times \sigma T_{a}^{4}
\end{aligned}
$$

where $\sigma$ is the Stefan-Boltzmann constant, $T_{a}$ and $q_{a}$ the air temperature and specific humidity (respectively), at screen-level, and $\sigma_{c}$ is the cloud coverage $\left(\sigma_{c} \in[0,1]\right)$. The $\sigma_{c}$ parameter was measured at Francazal. The regression coefficients $\beta$ and $\beta^{\prime}$ were determined from the available values of $R a$ at the MUREX site and from the cloud coverage $\sigma_{c}$ at Francazal. The regression parameters obtained (for 1995) are $\beta=11.3 \mathrm{Wm}^{-2}$ and $\beta^{\prime}=0.9685$, with a square correlation coefficient $\left(r^{2}\right)$ of $73 \%$ and a standard error of $25 \mathrm{Wm}^{-2}$. When cloud coverage observations were not available, Eq. (1) was applied with $\sigma_{c}=0$, and $\beta=43.9 \mathrm{Wm}^{-2}$ and $\beta^{\prime}=1.0056$. In this case, the value of $r^{2}$ is $70 \%$ and the standard error is $25 \mathrm{Wm}^{-2}$. The same method was applied to the 1996 and 1997 datasets, with similar results. The 3-y measurements of the atmospheric forcing data $\left(P, R g, R a, T_{a}, q_{a}, U\right)$, surface fluxes $(R n, H, L E, G)$, and soil moisture, are summarised in Figs. 2, 3, and 4 .

The main differences between the three years are related to changes in the rainfall regime: 1995 was characterised by evenly distributed precipitation $(770 \mathrm{~mm}) ; 1996$ was the wettest year $(860 \mathrm{~mm})$, and 1997 was a dry year $(540 \mathrm{~mm})$ marked by a spring and an autumn drought (Fig. 2). The droughts of 1997 had a significant impact on the measured surface fluxes (Fig. 4): the sensible heat flux exceeded evapotranspiration during the autumn 1997 (i.e. from September onward), and the monthly evapotranspiration never exceeded $300 \mathrm{MJ} \mathrm{m}^{-2}$, contrary to that which occurred in 1995 and 1996. Note that the reduced maximum monthly evapotranspiration in 1997 was also related to lower values of incoming solar radiation (Fig. 2).

\subsection{Deep soil moisture measurements}

Deep soil moisture profiles were obtained on a weekly basis from neutron probe measurements. the measured soil moisture profiles corresponded to $0.10-0.15 \mathrm{~m}$ intervals, from the surface to $1.35 \mathrm{~m}$. The soil water potential was estimated from tensiometric measurements at $0.1 \mathrm{~m}$ intervals within the $0.3 \mathrm{~m}$ surface layer 

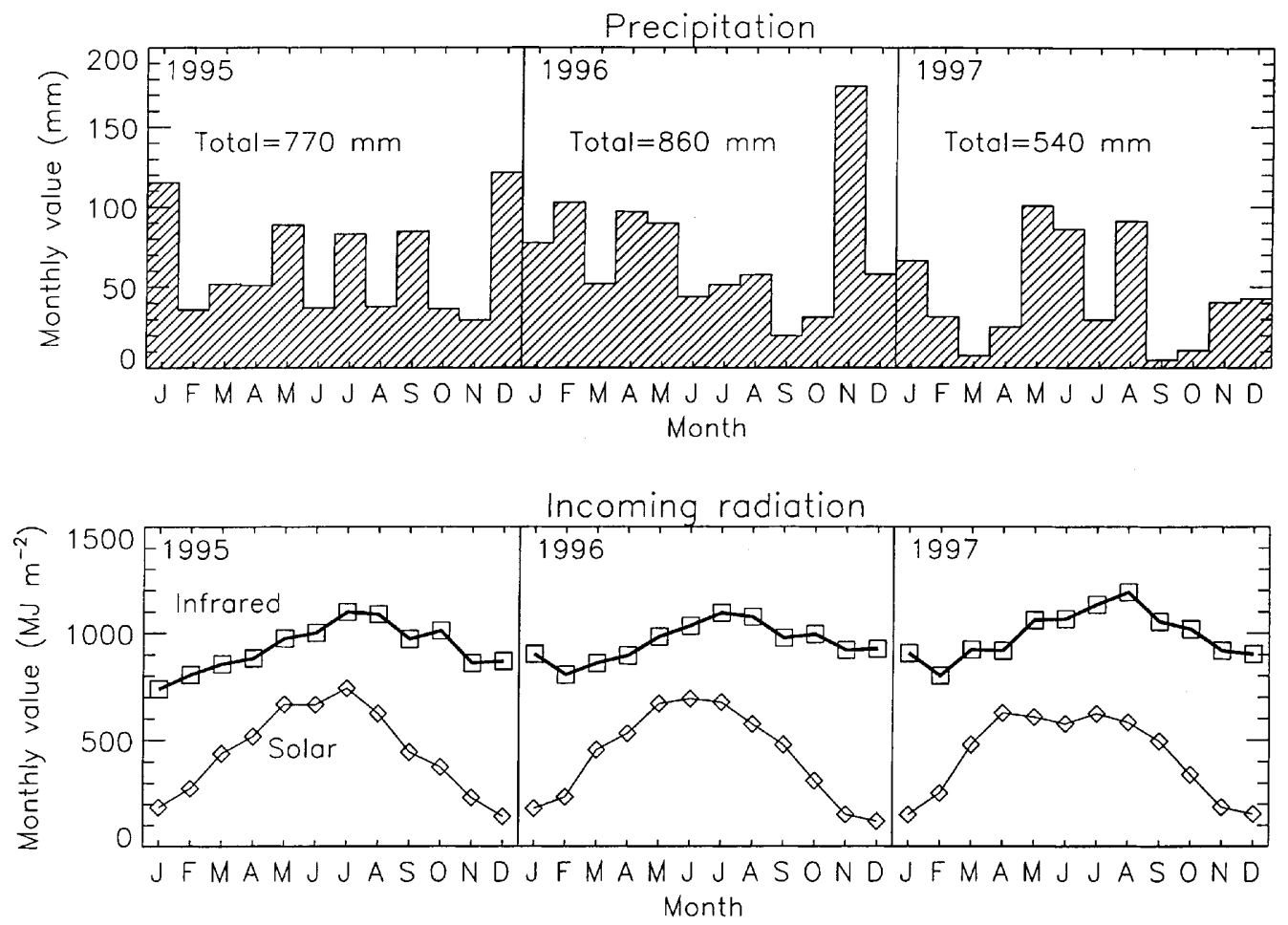

Fig. 2. The measured precipitation and incoming radiation, $R g$ and $R a$, over the MUREX fallow in 1995, 1996, and 1997. The plotted precipitation and incoming radiation are monthly sums of the 30-min measured values

and at $0.2 \mathrm{~m}$ intervals below, down to $1.3 \mathrm{~m}$. The measurements were performed at three positions within the fallow site. They were selected after a preliminary gravimetric water contents survey according to the method proposed by Vachaud et al. (1985). In this study, the average value is considered. Once properly calibrated, the neutron probe technique allows accurate measurements of the soil water content. The average volumetric soil moisture measurements of the three years are displayed in Fig. 4. Again, the three annual cycles contrast sharply: soil water extraction never reached the $1 \mathrm{~m}$ depth in 1996, whereas water was extracted over the whole profile (i.e. as deep as $1.35 \mathrm{~m}$ ) in 1995 from July to September. In 1997, water was extracted below $1.35 \mathrm{~m}$, from August onwards. It is interesting to note that the precipitation occurring during the autumn 1997 was not large enough to refill the soil reservoir by the end of the year.
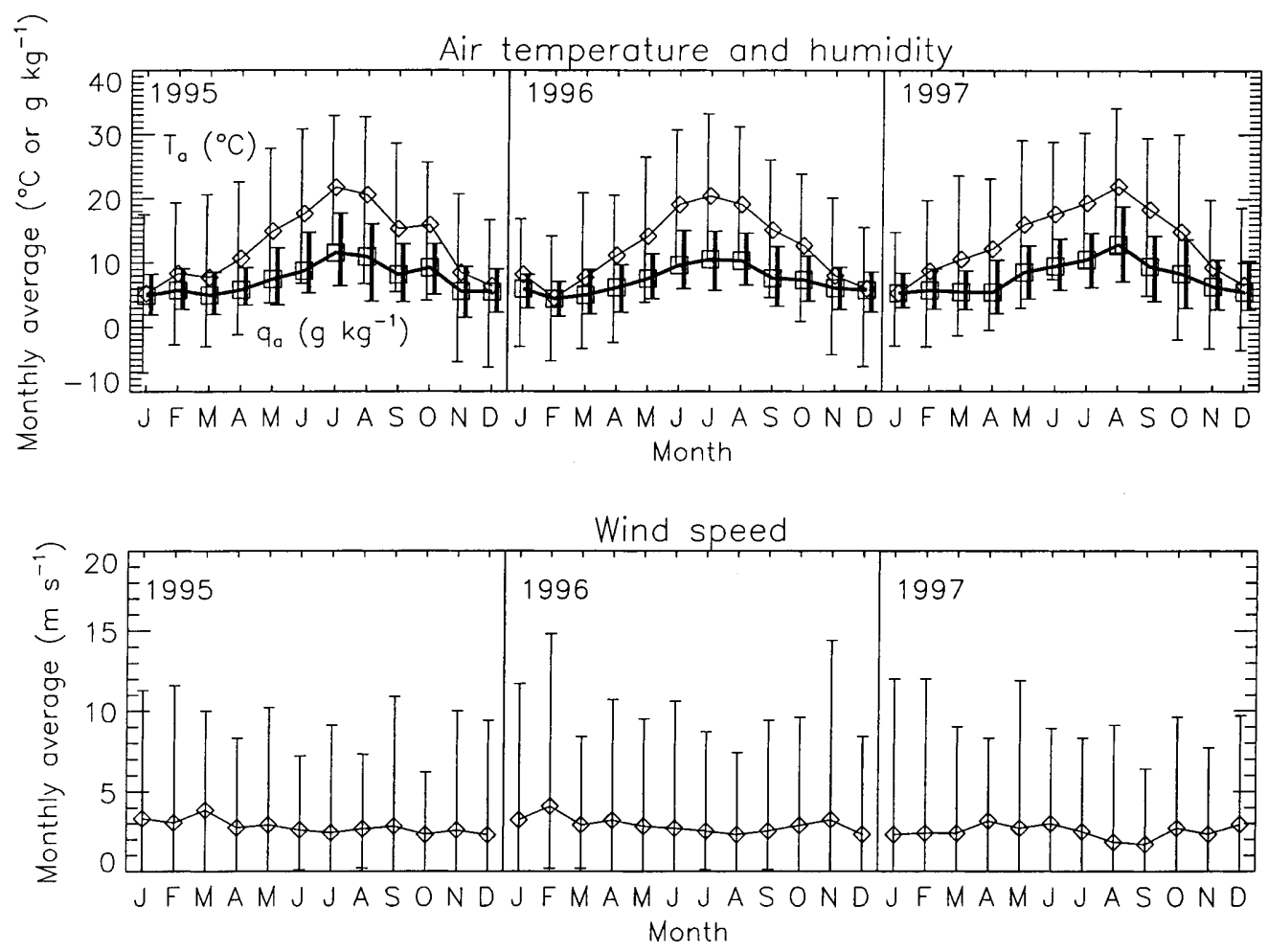

Fig. 3. As in Fig. 2, except for air temperature and humidity, $T_{a}$ and $q_{a}$ and wind speed. Air temperature, humidity, and wind speed are displayed as monthly means with maximum and minimum values indicated with bars. Air temperature and humidity are represented by diamonds with solid lines, and by boxes with solid thick lines, respectively 

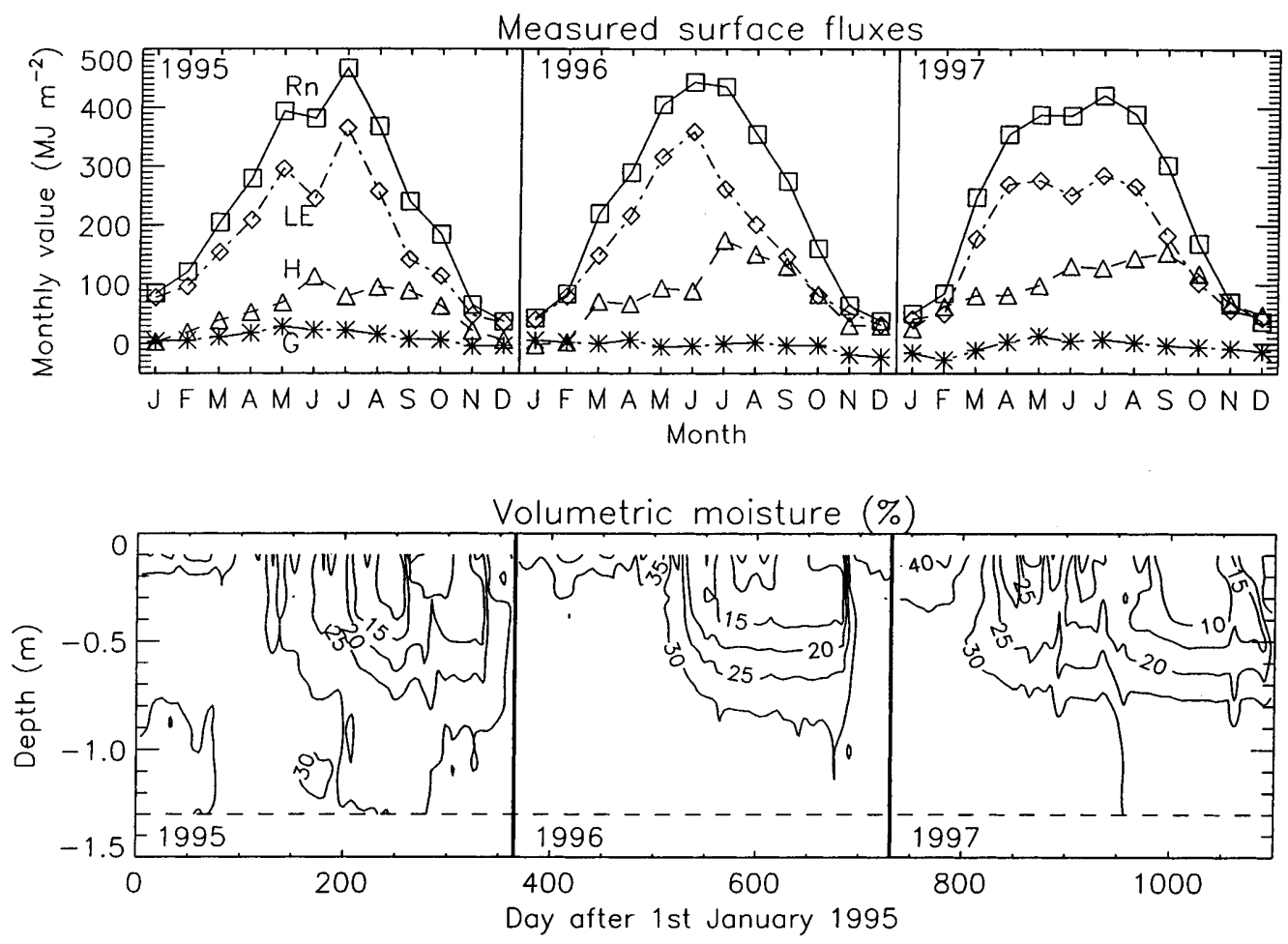

Fig. 4. Monthly sums of the measured fluxes (net radiation, $R n$; sensible heat flux; $H$; latent heat flux $L E$; and ground heat flux, $G$ over the MUREX fallow in 1995, 1996, and 1997 (note that $L E$ is estimated by difference), and a temporal diagram of the soil volumetric moisture within the $1.35 \mathrm{~m}$ soil layer as measured with a neutron probe over the MUREX fallow
Using the estimated soil moisture content change together with the measured precipitation and cumulated evaporation and cumulated evaporation, it is possible to assess the water balance on a weekly basis.

\subsection{Water balance}

According to the available measurements, the water balance of the MUREX fallow is rather unrepresentative of the climatic or large-scale evaporation over southwestern France. For example, the cumulated estimated evapotranspiration is about $800 \mathrm{~mm}$ for 1995, whereas the value of the cumulated precipitation for the same period is $770 \mathrm{~mm}$. The evaporation excess can be explained by a local subsurface soil water convergence which is likely to occur in this kind of terrain. The in situ measurements of bulk soil moisture, precipitation and evapotranspiration can be employed to estimate the weekly water excess $X$ s (Calvet et al., 1998a):

$X s=\Delta S+\Sigma L E-\Sigma P$

where $\Delta S$ is the change in the soil water storage $(S)$ between two consecutive measurements, from the surface to a depth of $1.35 \mathrm{~m}$, and $\Sigma L E$ and $\Sigma P$ are the cumulated values of evapotranspiration and precipitation over the period considered, respectively. The cumulated positive values of $X \mathrm{~s}$ are presented in Fig. 5, together with the cumulated precipitation. In general, winter is a period of runoff displaying negative values of $X$ s. Conversely, the inflow episodes (positive peak values of $X \mathrm{~s}$ ) are observed from the beginning of spring to the middle of the autumn. Their sum over any of the studied annual cycles represents a deep water gain of about $200 \mathrm{~mm}$. The inflow can be due to lateral movements of water and (to a lesser extent) to capillarity rises from soil layers deeper than $1.35 \mathrm{~m}$. It produces a significant contribution to the local water balance, especially during the drying periods.

Simple calculations based on tensiometric measurements at the bottom of the profile indicate that capillarity rises from below $1.35 \mathrm{~m}$ do not exceed $4 \mathrm{~mm}$ in 1995 (Calvet et al., 1998a). Therefore, most of the water excess seems to be due to lateral movements of water. In the case of the MUREX fallow, part of the inflow may be supplied by upstream rain and irrigation drained water (a large proportion of the uphill fields consists of irrigated maize).

\section{Vegetation dynamics and the water and carbon dioxide fluxes}

Fallow vegetation resulting from set-aside cultivated fields is currently widespread in western Europe. The vegetation of the MUREX fallow consists of many $\mathrm{C}_{3}$ herbaceous plant species whose growing cycles overlap, contributing to maintain a rather dense, evergreen canopy. In order to characterise the fallow, the specific contribution of each species was determined using a simplified point quadrats method (Daget and Poissonet, 1971), and the spatial heterogeneity of the vegetation was investigated. Over a total number of 81 species identified on the site, the plants making up the canopy at a given time represented 38 to 55 different species. However, the fallow was dominated by a few species only: Brachypodium sp ( $45 \%$ of the plants), and 

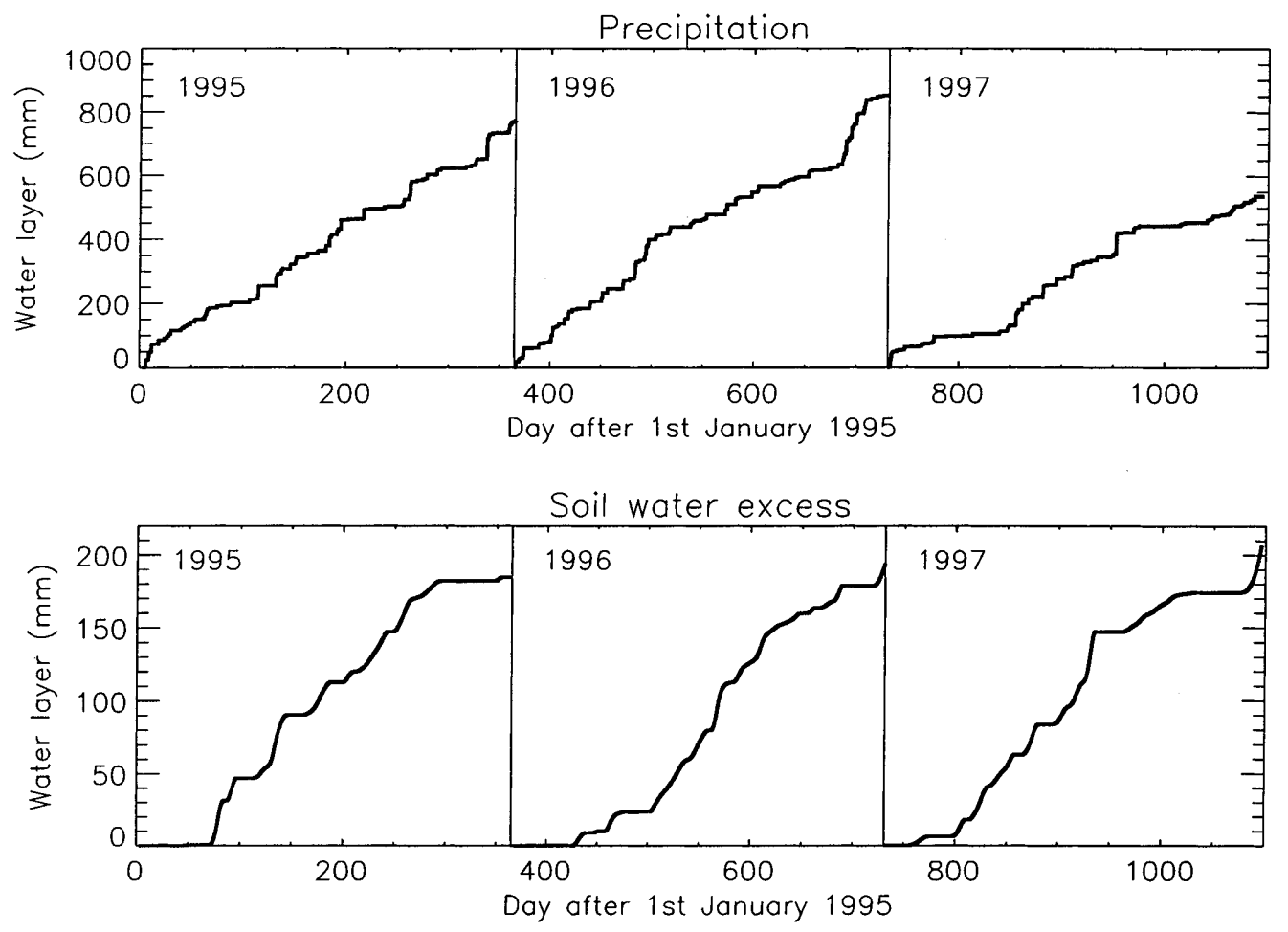

Fig. 5. Cumulative precipitation and positive values of the water excess derived from the total soil moisture content, precipitation and evapotranspiration measurements over the MUREX fallow in 1995 , 1996, and 1997
Potentilla reptans $(22 \%)$ were the main dominant species, together with Erigeron canadensis, Epilobium tetragonum, and Rumex acetosa. This kind of herbaceous canopy represents the first stage of a plant succession (once cultivation has stopped) leading to a Quercus pubescens forest climax. Despite the wide area covered by this type of fallow, they have not been intensively investigated until now, especially concerning their primary production, seasonal dynamics, and the role they play in land-atmosphere exchanges.

In this section, specific biomass and ecophysiological measurements performed with in the framework of MUREX are presented. Green leaf area index $(L A I)$ and biomass measurements were performed by destructive planimetric measurements by CESBIO and CNRM. Figure 6 shows the measured values of $L A I$ together with the dead and living above-ground biomass over the three annual cycles. The dead vegetation residues tend to form a rather dense vegetal mulch at the soil surface. In 1995, the fallow was mown on DoY 152, thus increasing the mulch dead biomass. The rather large scatter of $L A I$ is due to the heterogeneous vegetation species distribution. However, clear interannual differences emerge from the series of observations displayed in Fig. 6. In particular, the maximum $L A I$ was lower in 1997 than in 1996 (about 2 and $3.5 \mathrm{~m}^{2} \mathrm{~m}^{-2}$, respectively), consistent with the precipitation deficit of 1997, compared with 1996.

As far as root biomass is concerned, an average value of $160 \mathrm{~g} \mathrm{~m}^{-2}$ was obtained by CESBIO from measurements performed on five different dates in 1995. It must be noted that most of the roots were found in the $0.25 \mathrm{~m}$ surface soil layer. A few roots, representing a very small part of the total root biomass, were observed in deeper layers (down to $0.70 \mathrm{~m}$ ). This implies that a large part of the soil water extraction occurring below $0.25 \mathrm{~m}$ (Fig. 4) is due to capillarity rises from deeper soil layers, but direct root extraction from below $0.25 \mathrm{~m}$ may occur. The deep root extraction could not be quantified.

Using the shortwave radiation measurements mentioned before, it was possible to determine the albedo $(\alpha)$ of the canopy: $\alpha=0.20 \pm 0.04$ in 1995 and 1996. In 1997, a slightly higher value was obtained: $\alpha=0.21 \pm 0.04$. Again, this higher value may be related to a quicker wilting and yellowing of the leaves due to the considerable water stress of 1997.

Water and carbon dioxide fluxes in the soil-plantatmosphere continuum widely depend on the vegetation. A specific study was conducted during the 1997 and 1998 growing seasons to determine the seasonal and diurnal dynamics of the vegetation features as influenced by environmental conditions.

Stomatal conductance and water potential were measured on leaves of major species from the early spring to the autumn of 1997 , along with the biomass and LAI dynamics of the field vegetation. The main conclusions of this series of biophysical measurements for the MUREX fallow are: (1) the plant species exhibited low stomatal resistances, indicating their potential ability to maintain high $\mathrm{CO}_{2}$ and water vapour fluxes; (2) some differences between coexisting species occurred, concerning diurnal variations of stomatal conductance and water potential; (3) the diurnal variations of leaf stomatal resistance and water potential differed greatly according to air saturation deficits and soil moisture conditions.

Carbon dioxide fluxes were measured during the 1997 summer period, and in 1998. Two methods were 

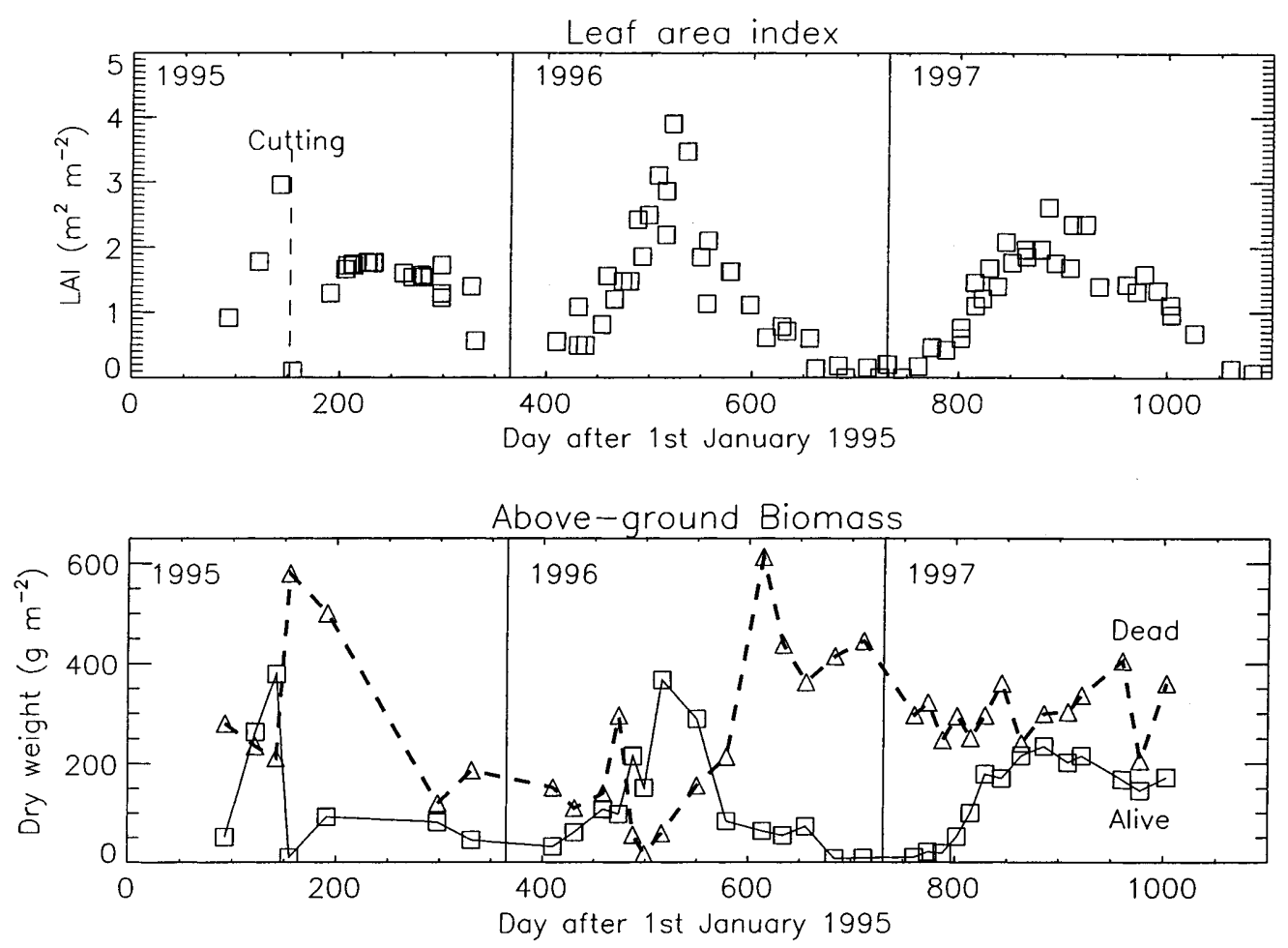

Fig. 6. The green leaf area index and above-ground green biomass (boxes) and necromass (thick dashed line and triangles) measured over the MUREX fallow in 1995, 1996, and 1997. The discontinuity on day 152 is due to the cutting of the vegetation employed: chamber measurements were performed by CESBIO (using a Ciras-1 PPSystems infrared gas analyser), and CNRM used the eddy-correlation method (using a SOLENT ultrasonic anemometer, and a LICOR LI-6262 infrared gas analyser). The chamber measurements enable estimation of the different components of the net $\mathrm{CO}_{2}$ flux: (1) the unscreened chamber over the undisturbed canopy provides the net $\mathrm{CO}_{2}$-flux; (2) by screening the chamber over the undisturbed canopy, one obtain the total soil and leaf respiration (photosynthesis is suppressed); and (3) by cutting the vegetation before the observation, an estimate of soil respiration is obtained (photosynthesis and leaf respiration are suppressed). The first term should correspond to the atmospheric flux measured by the eddy-correlation method. Figure 7 presents a series of bioclimatic variables observed on DoY 247 in 1997. The atmospheric net $\mathrm{CO}_{2}$-flux obtained by the two methods (either chamber or eddy-correlation measurements) are in good agreement. The canopy net assimilation $A n$ (i.e. the quantity of $\mathrm{CO}_{2}$ integrated into the vegetation biomass through the photosynthesis process) may be much higher than the measured atmospheric $\mathrm{CO}_{2}$-flux presented in Fig. 7 because the plant may absorb the $\mathrm{CO}_{2}$ emitted by the soil, also. An estimation of $\mathrm{An}$ is the difference between the atmospheric $\mathrm{CO}_{2}$-flux and soil respiration: on DoY 247 in 1997 (Fig. 7), the obtained net assimilation reaches $0.5 \mathrm{mg} \mathrm{m}^{-2} \mathrm{~s}^{-1}$ at about $0900 \mathrm{LST}$ and $1500 \mathrm{LST}$, whereas the atmospheric $\mathrm{CO}_{2}$-flux does not exceed $0.3 \mathrm{mg} \mathrm{m}^{-2} \mathrm{~s}^{-1}$. The $A n$ and evapotranspiration 'plateau' observed between 0900 and 1500 LST (Fig. 7) may be related to stomatal closure due to high temperatures or to a large saturation deficit of the air within the canopy. It is interesting to note that the average behaviour of the canopy in terms of stomatal conductance may result from distinct diurnal variations of this parameter from one plant species to another (Fig. 7).

\section{Surface soil moisture and temperature}

\subsection{Surface soil moisture measurements}

Surface soil moisture was estimated either manually (by weighing samples collected in the field) or automatically (in situ capacitive measurements).

In 1995, soil moisture profiles within the top 5-cm soil layer were measured manually, twice a day, during two 30-day intensive observing periods (IOPs) in spring and autumn: 1-from DoY 114 to 143 for the spring-IOP, 2from DoY 269 to 298 for the autumn-IOP. Each measurement consisted of the gravimetric moisture of 36 (6 layers $\times 6$ sites) soil samples, determined by a direct oven-drying method. The soil moisture content was measured: (1) from the surface to the $5-\mathrm{cm}$ depth with a resolution of $1 \mathrm{~cm}$, and (2) for the $0.5-\mathrm{cm}$ surface layer. The volumetric moisture $w\left(\mathrm{~m}^{3} \mathrm{~m}^{-3}\right)$ is derived from the gravimetric measurements $\theta(\mathrm{kg}$ of water per $\mathrm{kg}$ of dry soil) by:

$w=\frac{\rho_{b}}{\rho_{w}} \times \theta$

where $\rho_{b}$ is the soil dry bulk density and $\rho_{w}$ the density of liquid water $\left(\mathrm{kg} \mathrm{m}^{-3}\right)$. The value of $\rho_{b}$ did not change significantly from one IOP to the other: the measured values over the surface 5-cm layer are $1452 \pm 87$ and $1450 \pm 114 \mathrm{~kg} \mathrm{~m}^{-3}$ on DoY 123 and 286 of 1995 , respectively. 

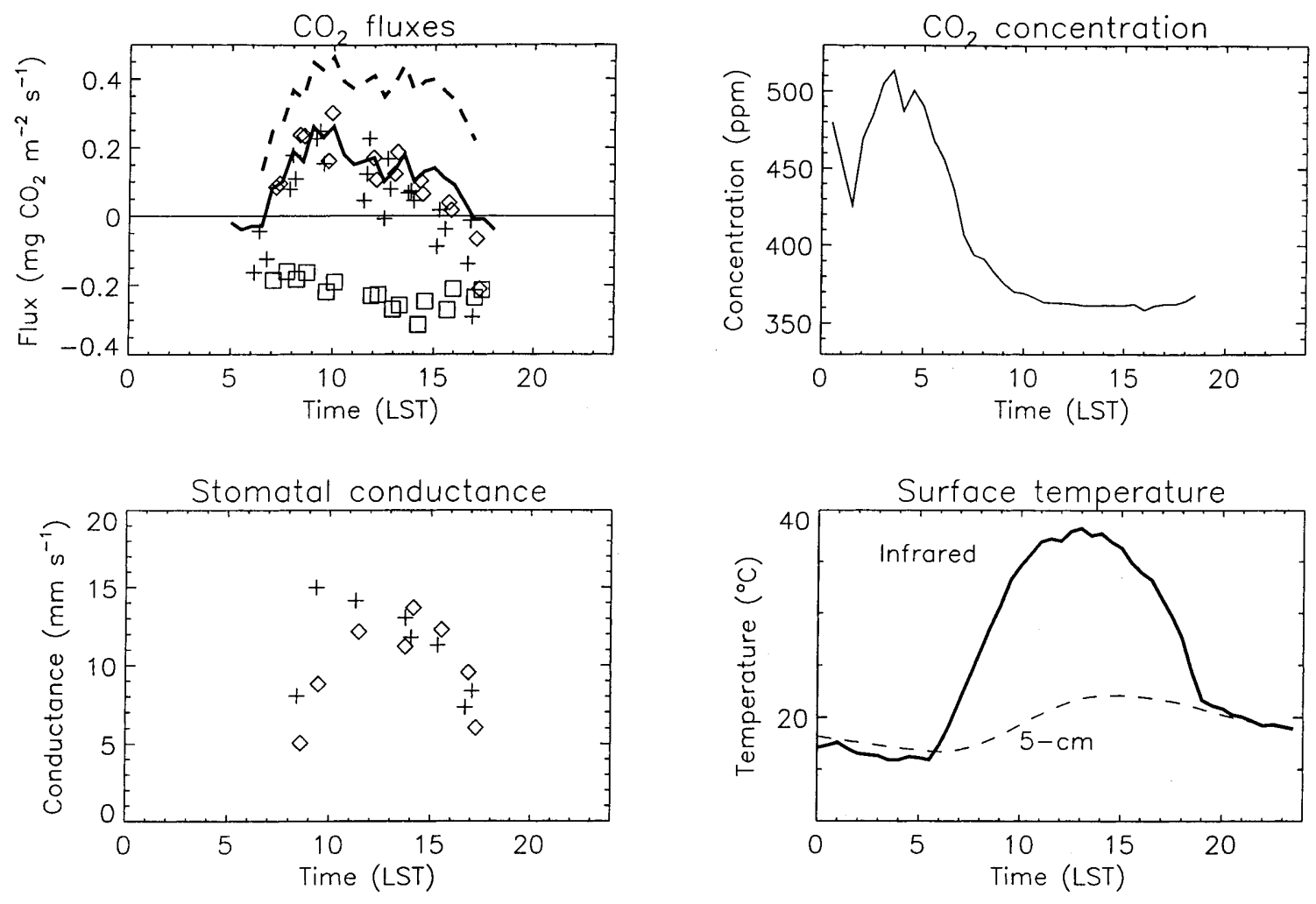

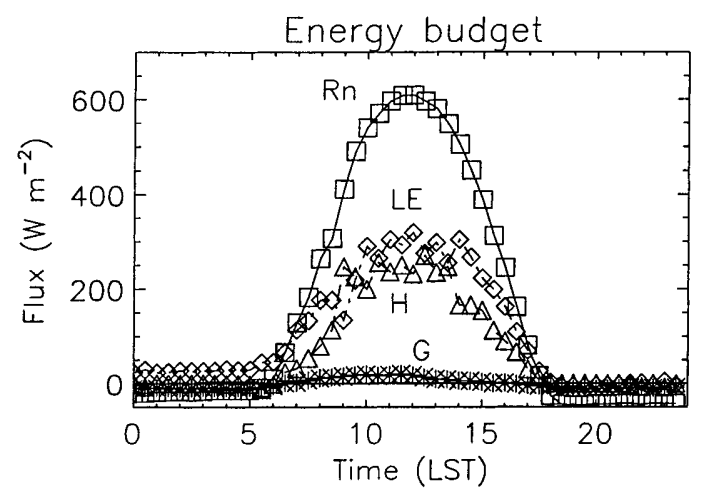

Fig. 7. Measurements characterising the bioclimatological functioning of the MUREX fallow on DoY 247 in 1997. The atmospheric $\mathrm{CO}_{2}$ flux and concentration are measured at $2.7 \mathrm{~m}$ above the soil surface (solid lines); chamber measurements of the net $\mathrm{CO}_{2}$ flux are obtained over Potentilla- and Brachypodium-dominated spots (pluses and diamonds, respectively); the negative $\mathrm{CO}_{2}$ flux represented by boxes corresponds to chamber measurements of soil respiration. The $\mathrm{CO}_{2}$ flux represented by the dashed line is an estimation of daytime net assimilation given by the difference between the atmospheric $\mathrm{CO}_{2}$ flux

The automatic method was implemented at the end of 1996. Four capacitive probes (ML1 ThetaProbe, Delta-T Devices 1996) were inserted into the soil surface and kept vertical by using an adequate frame. The output volumetric moisture represents an integrated value over the top $6-\mathrm{cm}$ at the soil surface. The observations were recorded on a 15 -min basis, and a linear correction was applied to the raw data according to manual measurements (oven-drying method). After calibration, the rms difference between the ThetaProbe data and the reference measurements was about $0.01 \mathrm{~m}^{3} \mathrm{~m}^{-3}$.

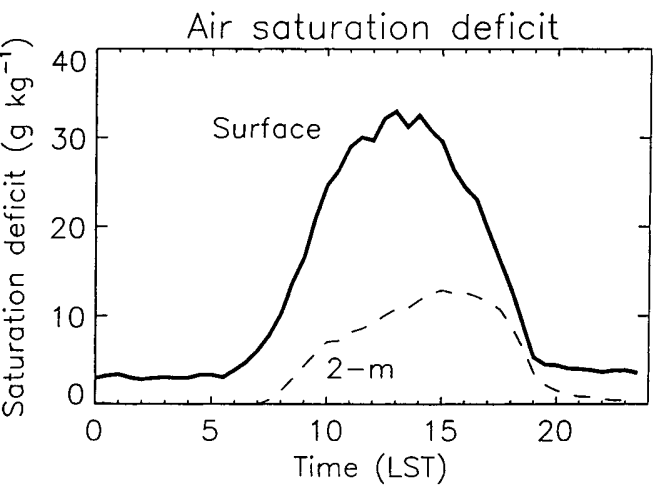

and soil respiration. In situ measurements of leaf stomatal conductance are obtained over Potentilla- and Brachypodium-dominated spots (pluses and diamonds, respectively). The surface temperature is either infrared-derived (thick line) or measured in the soil (dashed line), here at $5-\mathrm{cm}$. The energy budget is given by the SAMER system (net radiation $R n$; heat flux $H$ : latent heat flux $L E$; and ground heat flux $\mathrm{G})$. The air saturation deficit (dashed line) is obtained from screenlevel air temperature and humidity data, and the deficit at the surface (solid thick line) is computed from the infrared-derived temperature

The average surface soil moisture is presented in Fig. 8, together with the bulk soil moisture obtained from the neutron-probe measurements over the $1.35 \mathrm{~m}$ profile. Interestingly, the measurements of 1997 show that the surface soil moisture can be much lower than the bulk soil moisture during long periods (e.g. September and October 1997). This is related to the vertical gradients of texture and bulk density observed on the site: the wilting-point soil moisture is lower close to the surface than deeper in the soil, permitting lower values of the soil water content. Direct soil evaporation is expected to have a minor influence on the decrease of 

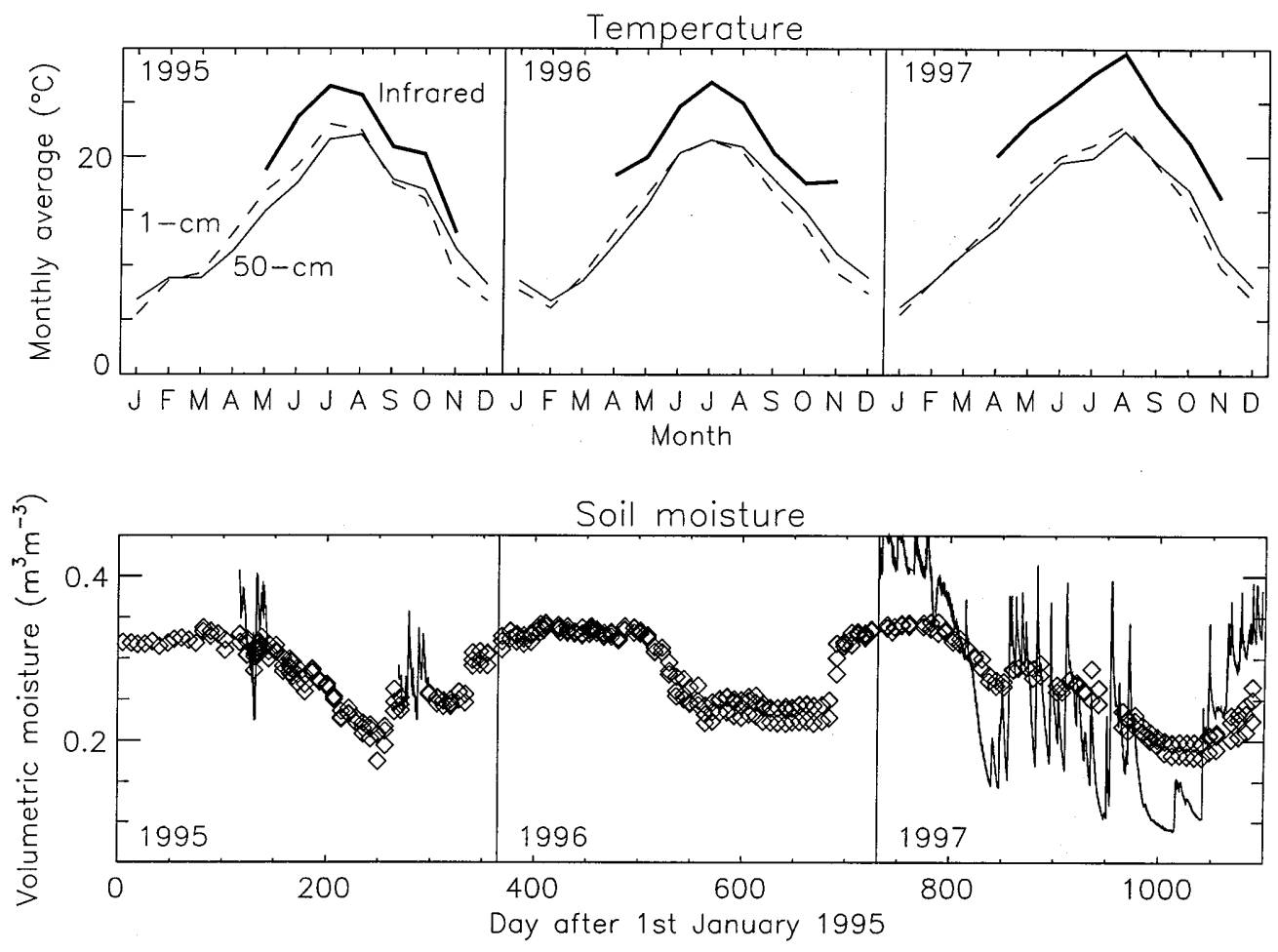

Fig. 8. Monthly averages of the measured infrared-derived surface temperature (thick solid line), and of the soil temperature at $1-\mathrm{cm}$ (dashed line) and $50-\mathrm{cm}$ (solid line) below the soil surface, and the measured soil water content of the $1.35 \mathrm{~m}$ column (diamonds) and surface soil water content over the top 5-6 cm (solid line), in 1995, 1996, and 1997 surface soil moisture because of the mulch screening effect.

\subsection{Surface temperature and emissivity}

In this study, six temperatures characterising the surface were measured: the infrared temperature $\left(T_{I R}\right)$ is obtained from an infrared radiometer, and the soil temperature at $1,5,20,50$, and $120 \mathrm{~cm}$ below the soil surface $\left(T_{-1}, T_{-5}\right.$ and $T_{-20}, T_{-50}$, and $T_{-120}$, respectively) were measured with platinum-resistance thermometers. The surface temperature $T_{S}$ was derived from $T_{I R}$ and an effective emissivity $\left(\varepsilon_{e f f}\right)$ :

$T_{s}=\left(T_{I R}^{4} / \varepsilon_{e f f}\right)^{1 / 4}$

The value $\varepsilon_{e f f}=0.977$ could be estimated from Eq. (4) by assuming that $T_{s}=T_{-1}$ when no vertical gradients of temperature were observed at the soil surface (i.e. $T_{-1}=T_{-5}$ ) after sunset, between 2000 and 2100 Local Standard Time (LST).

The thermal emissivity of the surface $\left(\varepsilon_{s}\right)$ is a parameter of the SVATs. The value of $\varepsilon_{s}$ can be retrieved from $T_{S}$ and the radiation measurements. Indeed, the measured upwelling thermal emission of the surface $(R s)$ can be written as:

$R s=\varepsilon_{s} \sigma T_{s}^{4}+\left(1-\varepsilon_{s}\right) R a$

The value $\varepsilon_{s}=0.97$ minimises the rms difference between the measured value of $R s$, and the value given by Eq. (5): the rms difference is $10.6 \mathrm{Wm}^{-2}$ and over 1995 , the mean bias is less than $2 \mathrm{Wm}^{-2}$.

\section{Modelling approaches}

The main purpose of the MUREX experiment is to improve the representation of the land-surface processes in atmospheric models. Improved numerical experiments and new analysis algorithms and parametrisations based on these data are presented in other studies. In particular, the ISBA scheme was employed in several configurations to analyse the MUREX data: (1) the data of 1995 were used to test an assimilation technique to analyse the total soil water content from surface soil moisture or surface temperature (Calvet et al., 1998a); and (2) a new version of ISBA including $\mathrm{CO}_{2}$ assimilation and plant growth (ISBA-Ags) was applied to the data of 1995 and 1996 (Calvet et al., 1998b).

In this study, simulations performed by four models over the 1995 annual cycle (ISBA, MAGRET, SiSPAT, and $\mathrm{ALiBi}$ ) are compared. All the models are driven by measurements of incoming radiation, precipitation, atmospheric pressure, air temperature and humidity, and wind speed at a reference level. Also, vegetation characteristics such as leaf area index and canopy height must be prescribed. These parameters may change with time. The ISBA (Noilhan and Planton, 1989) and MAGRET (Lagouarde, 1991; Courault et al., 1996) models have similar functions and input and output variables: they both describe the water division between the vegetation transpiration, the drainage, the surface runoff and the soil moisture increase or decrease, and they both solve a single energy budget and compute the surface temperature. This kind of models represents a particularly robust approach to describe how land surface functions over long periods, at low computing 
costs. The SiSPAT model (Braud et al., 1995) belongs to a more complex class of SVATs: the vegetation structure is more detailed, and a multilayer description of the soil is employed. Conversely, the ALiBi model (Olioso, 1992) was designed to analyse remote sensing data such as infrared brightness temperature in order to diagnose evapotranspiration and photosynthesis without monitoring the root-zone soil moisture. In ALiBi, the characterisation of the physiological plant functioning is improved. In this study, the four models are run over 1995 with the interpolated $L A I$ curve obtained by Calvet et al. (1998a) from the observed values. Also, the photosynthesis modelled by ISBA-Ags and ALiBi are compared.

\section{$6.1 \operatorname{ISBA}$}

In this study, the most recent standard version of ISBA (Noilhan and Mahfouf, 1996), implemented within the Météo-France global climate model ARPEGE by Mahfouf et al. (1995) is employed. The ISBA scheme simulates the surface fluxes $(L E, H, G)$ and predicts the evolution of the surface state variables using the equations of the force-restore method of Deardorff (1977, 1978). Five variables (surface temperature $T_{s}$, mean surface temperature $T_{2}$, surface soil volumetric moisture $w_{g}$, total soil volumetric moisture $w_{2}$, and the canopy interception reservoir $W_{r}$ ) are obtained through prognostic equations. It must be noted that ISBA does not need a root distribution: $w_{2}$ is the volumetric soil moisture associated to a bulk layer of thickness $d_{2}$ including the root zone. The surface soil moisture $w_{g}$ is computed to estimate the evaporation from the soil surface, whereas the transpired water is extracted from $w_{2}$. The surface water quantity from $w_{g}$ is included in $w_{2}$. Initial values of soil variables are required. In this study, the contribution of the water excess caused by a perched aquifer or by deep capillarity rises (measured positive values of $X \mathrm{~s}$ ) is accounted for in the water budget as in
Calvet et al. (1998a): the $X \mathrm{~s}$ term is very significant in the case of the MUREX fallow, and the time series of $X \mathrm{~s}$ must be prescribed in the evolution equation of $w_{2}$ in order to obtain a good agreement between simulated and observed values of both surface evapotranspiration and root-zone soil moisture. Furthermore, estimates of the deep temperature are required to avoid severe drifts of the cumulated model heat flux in the soil. In this study, the prescribed deep temperature is taken as the measured temperature at $50 \mathrm{~cm}$ below the soil surface $\left(T_{-50}\right)$.

The description of the surface fluxes $R n, H$, and $L E$ is detailed in Noilhan and Planton (1989). The main prescribed parameters of the surface involved in the flux calculation are: the surface albedo and emissivity ( $\alpha$ and $\varepsilon_{S}$, respectively), the momentum and thermal roughnesses ( $z_{0}$ and $z_{O h}$, respectively) and the vegetation $L A I$ and minimal stomatal resistance $\left(r_{\text {smin }}\right.$, expressed in units of $\mathrm{sm}^{-1}$ ). This latter term depends on the plant species making up the canopy, and in general must be calibrated. The surface albedo and emissivity are prescribed from measurements and $z_{0}$ is derived from the vegetation height estimates $(h)$ through: $z_{0}=0.13 \times h$. Table 1 displays the ISBA structure parameters either obtained from the in situ measurements, derived from the soil texture $\left(w_{\text {wilt }}, w_{s a t}\right)$, or calibrated $\left(w_{f c}, \gamma, \varepsilon_{s}, C_{v}\right.$, $\left.r_{\text {smin }}, z_{0} / z_{0 h}\right)$. The procedure to obtain calibrated values is detailed in Calvet et al. (1998a). Note that in this study, all the parameters were calibrated according to $R_{n}, H$, and $L E$, whereas the cumulative $G$ was also used in Calvet et al. (1998a). Therefore, the Table 1 parameter values (especially $C_{\mathrm{V}}$ and $z_{0} / z_{0 h}$ ) differ from those given by Calvet et al. (1998a). The calibrated ratio $z_{0} / z_{0 h}$ (Table 1) employed for ISBA (and MAGRET) reaches a high value of 450 , whereas a value of 10 is usually employed for small vegetation canopies. However, many authors have reported high values of $z_{0} / z_{0 h}$ (even higher than 450) for a wide range of surfaces (see Verhoef et al., 1997 for a review, and Troufleau et al., 1997). Verhoef et al. (1997) suggest that $z_{0} / z_{0 h}=10$ is probably too low for most natural surfaces.

Table 1. The soil and vegetation structure parameters over the MUREX fallow for ISBA and MAGRET

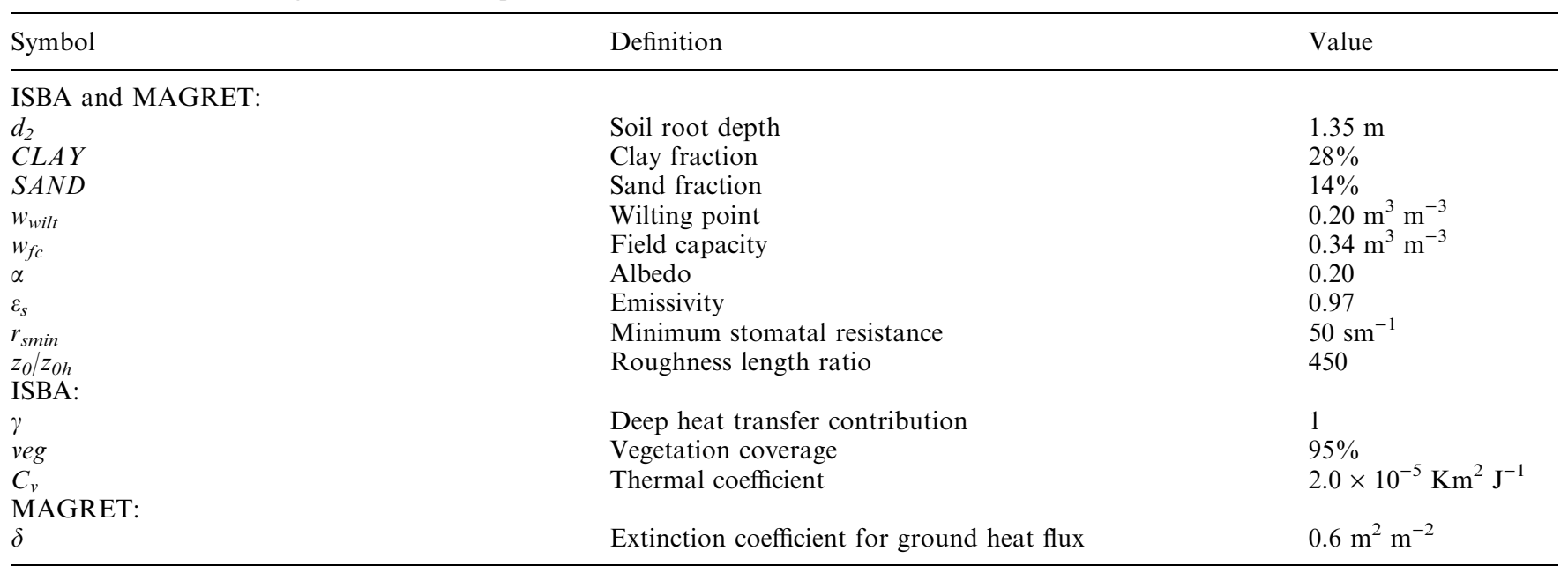




\subsection{MAGRET}

The working of MAGRET is detailed in Courault et al. (1996). It is very similar to ISBA. In particular, the input atmospheric, radiation, and vegetation variables are the same. Differences arise from the way evapotranspiration, and soil moisture are computed. Contrary to ISBA, bare soil evaporation and vegetation transpiration are not distinguished. Whereas they are calculated separately is ISBA, the total canopy evapotranspiration is obtained using a bulk canopy resistance including vegetation structure resistances, a resistance to soil evaporation related to the surface dry soil layer, and the plant stomatal resistance. This latter resistance is calculated in the same way as in ISBA. Concerning soil moisture, the two reservoir systems proposed by Jacquart and Choisnel (1995) is employed. Each reservoir corresponds to a layer of wetted soil, the thickness of which vary according to the computed loss (evapotranspiration) or gain (rainfall) of water. Since the MUREX water excess cannot be included in a bulk soil reservoir as in ISBA, the water excess was added to the precipitation prescribed for MAGRET (Table 2).

Another difference concerns the calculation of the ground heat flux $G$ and the effect of vegetation. In ISBA, $G$ is the residual of the energy budget. The obtained value of $G$ is employed in the pronostic equation for the surface temperature, weighted by a thermal coefficient including a vegetation term $C v$. In MAGRET, $G$ is computed from the temperature gradient at the surface and an exponential attenuation term depending on $L A I$ times the extinction coefficient $\delta$ (Table 1). The MAGRET model computes the diurnal evolution of the canopy albedo. In this study, the albedo module was inactivated and the average value of 0.2 was imposed as in ISBA.

\section{$6.3 \operatorname{SiSPAT}$}

In the SiSPAT model (Braud et al., 1995) the transfers in the soil are described in more detail: the vertical heterogeneity of the soil structure and texture is accounted for, and a root distribution must be prescribed. The heat and water exchanges are specified through Fourier and Richards' equations, and the soil prognostic variables are vertical profiles of temperature and soil matric potential. Consistent with the accurate description of the soil processes, the vegetation layer is depicted more precisely than in ISBA and MAGRET: the radiative transfer within the canopy is accounted for, together with separate energy budgets of vegetation and bare soil (Deardorff, 1978). As a lower boundary condition for the soil profile, the measured time evolution of matric potential at $1.3 \mathrm{~m}$ was imposed. Since no deep measurement of soil temperature was available in 1995, the average values of the 1996 and 1997 series (at $1.2 \mathrm{~m}$ ) were used.

In order to better described the particular behaviour of the MUREX fallow, the SiSPAT model was modified to account for the mulch effect (Gonzalez-Sosa et al., Submitted 1999). Indeed, Gonzalez-Sosa et al. (1999) showed that, using SiSPAT, water and energy transfer within the mulch layer must be explicitely described, especially after the vegetation cutting in 1995, on DoY 152. Accounting for the mulch greatly improves the SiSPAT simulations over MUREX. To summarise, the mulched simulations present higher values of bulk soil moisture and lower values of evapotranspiration. The flux simulation after the vegetation cutting of DoY 152 is erroneous in non-mulched simulations. In particular soil evaporation is greatly overestimated, which brings about a rapid soil moisture depletion affecting the quality of the flux simulation afterwards. In the simulations presented, SiSPAT was run with the same $r_{\text {smin }}$ than ISBA and MAGRET (Table 1). Displacement height and roughness length for momentum were calculated as a function of leaf area index and vegetation height (Shuttleworth and Wallace, 1985). The $z_{0} / z_{0 h}$ values are given by the formula of Brutsaert (1982, cited by Verhoef et al., 1997). The rooting depth varies with time from 0.5 to $0.7 \mathrm{~m}$ according to the observed soil moisture profiles. The maximum root density was set at $2 \times 10^{4} \mathrm{~m} \mathrm{~m}^{-3}$. A vegetation albedo of 0.15 was employed, and the bare soil or mulch albedo was calculated so that the total albedo equal 0.20 . The other vegetation parameters employed in SiSPAT are: the critical leaf potential $(-140 \mathrm{~m})$, and the total plant resistance $\left(3.210^{12} \mathrm{~s} \mathrm{~m}^{-1}\right)$.

As with ISBA and MAGRET, it was found that the water excess $X$ s must be added to the water input in order to simulate the water budget. In order to avoid the water loss due to interception by the mulch and the vegetation, the water excess was applied to the surface soil layer (instead of directly increasing the precipitation). The soil parameters employed in SiSPAT are displayed in Table 3. Five horizons are distinguished, from the surface to the total soil column depth $(1.35 \mathrm{~m})$. The employed suction curve, relating the volumetric water content $w$ to the matric potential $h$ (expressed in units of $\mathrm{m}$ ) consists of the Van Genuchten (1980) formula:

Table 2. The MUREX 1995 water budget as calculated by ISBA, MAGRET, and SiSPAT

\begin{tabular}{llllcrrr}
\hline Model & $\begin{array}{l}\text { Precipitation } \\
(\mathrm{mm})\end{array}$ & $\begin{array}{l}\text { Water } \\
\text { excess }(\mathrm{mm})\end{array}$ & $\begin{array}{l}\text { Evaporation } \\
(\mathrm{mm})\end{array}$ & $\begin{array}{l}\text { Drainage } \\
(\mathrm{mm})\end{array}$ & $\begin{array}{l}\text { Surface } \\
\text { runoff }(\mathrm{mm})\end{array}$ & $\begin{array}{l}\text { Soil moisure } \\
\text { change }(\mathrm{mm})\end{array}$ \\
\hline ISBA & 773 & 184 & 856 & 95 & 0 & 6 & $\begin{array}{r}\text { Error }(\mathrm{mm}) \\
\text { MAGRET }\end{array}$ \\
SiSPAT & 773 & - & 884 & 125 & 0 & -52 & 0 \\
\hline
\end{tabular}


Table 3. Soil parameters for the five SiSPAT's horizons, either measured or calibrated (*) using the SiSPAT model. They include the coefficients of the van Genuchten (VG) and Brooks and Correy (BC) models (Eqs. (6) and (7), respectively): $n$ and $h_{g}$ are shape and scale parameters of the VG model, and $c$ is the shape parameter of the $\mathrm{BC}$ model. The thermal conductivity $\lambda$ is given by Eq. (8) below $0.02 \mathrm{~m}$. The saturated water content and hydraulic conductivity are denoted by $w_{\text {sat }}$ and $K_{\text {sat }}$, respectively

\begin{tabular}{|c|c|c|c|c|c|c|c|}
\hline $\begin{array}{l}\text { Horizon } \\
(\mathrm{m})\end{array}$ & Porosity & $\begin{array}{l}w_{\text {sat }} \\
\left(\mathrm{m}^{3} \mathrm{~m}^{-3}\right)\end{array}$ & $n$ (VG model) & $\begin{array}{l}h_{g}(\mathrm{VG} \text { model }) \\
(\mathrm{m})\end{array}$ & $\begin{array}{l}K_{\text {sat }} \\
\left(\mathrm{m} \mathrm{s}^{-1}\right)\end{array}$ & $c$ (BC model) & $\begin{array}{l}\lambda \\
\left(\mathrm{Wm}^{-1} \mathrm{~K}^{-1}\right)\end{array}$ \\
\hline $0-0.005 \mathrm{~m}$ & 0.60 & 0.48 & 2.30 & -1.62 & $4.810^{-6}$ & 9.3 & $0.2(*)$ \\
\hline $0.02-0.1 \mathrm{~m}$ & 0.50 & 0.40 & 2.30 & -1.62 & $5.010^{-7}(*)$ & 9.3 & Eq. (8) \\
\hline $0.1-0.6 \mathrm{~m}$ & 0.45 & 0.35 & 2.27 & -1.70 & $7.510^{-8}(*)$ & 10.6 & Eq. (8) \\
\hline $0.6-1.35 \mathrm{~m}$ & 0.39 & 0.30 & 2.13 & -2.00 & $1.010^{-10}(*)$ & 33.3 & Eq. (8) \\
\hline
\end{tabular}

$$
\frac{w}{w_{\text {sat }}}=\left[1+\left(\frac{h}{h_{g}}\right)^{n}\right]^{\frac{2}{n}-1}
$$

where $w_{\text {sat }}$ is the saturated water content $\left(\mathrm{m}^{3} \mathrm{~m}^{-3}\right)$ and $h_{g}(\mathrm{~m})$ a scale factor. The hydraulic conductivity curve is given by Brooks and Corey (1964):

$K(w)=K_{\text {sat }}\left(w / w_{\text {sat }}\right)^{c}$

where $K_{\text {sat }}$ is the saturated hydraulic conductivity $\left(\mathrm{m} \mathrm{s}^{-1}\right)$ and $c$ a scale factor. Field estimates of $K_{\text {sat }}$ were obtained from infiltration tests performed using either tension disk infiltrometers (Vauclin and Chopart, 1992) or Guelph infiltrometers (Elrick and Reynolds, 1992), for the $0-30 \mathrm{~cm}$ surface layer and the deepest layers, respectively.

The thermal conductivity $\lambda$ (expressed in units of $\mathrm{Wm}^{-1} \mathrm{~K}^{-1}$ ) is given by the following equation, obtained from in situ measurements by the line source method (Laurent, 1989), completed with a laboratory characterisation of the volumetric moisture content $(w)$ dependence:

$$
\begin{aligned}
\lambda= & 0.729+0.135\left(w / w_{\text {sat }}\right) \\
& +1.26\left[1-\exp \left(-10.39\left(w / w_{\text {sat }}\right)^{1.84}\right)\right]
\end{aligned}
$$

The different terms of the MUREX water budget for 1995, including soil moisture change and total runoff, are simulated by ISBA, MAGRET, and SiSPAT (Table 2). Note that in the SiSPAT simulations the water budget is not completely balanced (error of $15 \mathrm{~mm}$ ) because of numerical cumulative inaccuracies occurring during soil moisture saturation. The ALiBi model presented below does not consider soil moisture change.

\subsection{ALiBi}

The ALiBi model was proposed by Olioso (1992) to relate evapotranspiration and photosynthesis to reflectance and infrared brightness temperature measurements. In order to derive evapotranspiration and photosynthesis the ALiBi model has to be used in an inverse mode (Olioso et al., 1996b): the modelled thermal brightness temperature is fitted to temperature measurements by adjusting some input parameters (usually related to water transfers through the plants).
Like SiSPAT, the ALiBi model is a two-layered energy balance model. Energy balance fluxes, as well as photosynthesis, are calculated using detailed descriptions of radiative transfer, turbulent transfer, water transfer, stomatal conductance and leaf photosynthesis.

The vegetation conductance $g_{s}$ is given by the sum of the leaf stomatal conductances over the whole canopy. Leaf stomatal conductances depend on incident PAR at leaf surface, leaf water potential and air saturation deficit at leaf surface (Winkel and Rambal, 1990). Another important equation describes water transfers from the soil to the leaves, where transpiration occurs. Like SiSPAT, it follows Van den Honert's formulation and relates transpiration $\left(L E_{t}\right)$ to the variation of water potential between the soil and the leaves ( $h$ and $h_{v}$, respectively) by means of an hydraulic conductance $\left(G_{p}\right)$, assumed constant for a given day:

$L E_{t}=G_{p}\left(h-h_{v}\right)$

A detailed description of water transfer, stomatal conductance and photosynthesis calculation was presented by Olioso et al. (1996a).

In the case of the MUREX dataset, evapotranspiration, canopy energy fluxes and photosynthesis were estimated by inverting the ALiBi model daily, according to the measured thermal brightness temperature $\left(T_{I R}\right)$ at midday (174 days between DoY 125 and 317 in 1995): each day, the simulated midday $T_{I R}$ was fitted to the measured value $( \pm 0.25 \mathrm{~K})$ by adjusting the hydraulic conductance parameter $G_{p}$. The other necessary inputs were: (1) either directly measured (LAI, canopy height, air temperature, air humidity and wind speed at a reference level above the canopy, solar and atmospheric radiations, atmospheric pressure), (2) computed from measured inputs (incident PAR, solar and PAR diffuse fraction and atmospheric radiation in the spectral range of the thermal radiometer), and (3) estimated from the values obtained for a soyabean crop in Avignon (Olioso et al., 1996a). The latter parameters consisted of soil thermal characteristics, leaf aerodynamic properties, parameters for stomatal conductance and leaf photosynthesis, optical properties of leaves and soil and leaf angle distribution. In particular, a maximum leaf stomatal conductance of $15 \mathrm{~mm} \mathrm{~s}^{-1}$ was employed. The root zone water potential and the soil temperature at a depth of $1 \mathrm{~m}$ were set to constant average values of $-0.5 \mathrm{MPa}$ and $17^{\circ} \mathrm{C}$, respectively. Soil moisture in the 
first $5 \mathrm{~cm} w_{g}$, which determines the soil evaporation in ALiBi was either measured (DoY 125 to 143 and 270 to 298), or set to arbitrary values of $0.2 \mathrm{~m}^{3} \mathrm{~m}^{-3}$ in the driest period (DoY 228 to 255) and $0.3 \mathrm{~m}^{3} \mathrm{~m}^{-3}$ elsewhere. It was found that the value of $w_{g}$ has little influence on the ALiBi outputs in the case of MUREX.

\section{Model validation and comparison}

The model performances can be assessed by comparing the model outputs with the measured values of surface fluxes, and for ISBA, MAGRET, and SiSPAT, the surface temperature and the total soil moisture.

\subsection{Surface fluxes}

The values of the simulated instantaneous and cumulated fluxes obtained with the structure parameters listed in Tables 1 and 3 are compared with the observed values in Table 4 and in Fig. 9, respectively. Figure 10 presents the smoothed daily evapotranspiration over the 1995 annual cycle, either measured by the SAMER system or modelled by ISBA, MAGRET, ALiBi, and SiSPAT. the ALiBi simulations do not cover the entire annual cycle, since they rely on $T_{I R}$ measurements, available in summer and autumn 1995, only. The errors affecting the simulated fluxes are listed in Table 4 in terms of rms error, mean bias (simulated minus observed), and skill score. The model skill score $E$ is defined as:

$$
E=1-\frac{\sum_{i}\left(x_{i O B S}-x_{i M O D}\right)^{2}}{\sum_{i}\left(x_{i O B S}-\overline{x_{O B S}}\right)^{2}}
$$

where $x$ are half-hourly values of the flux, either measured or simulated $(O B S$ and $M O D$ subscripts, respectively). A value of $E$ of $100 \%$ corresponds to perfect simulations and values of $E$ close to 0 correspond to a basic representation of $x$ by its constant average value. Negative values of $E$ show that the model is not adequate. In general, the four models perform realistic simulations of the surface fluxes. However, SiSPAT tends to underestimate evapotranspiration after the vegetation cutting (Fig. 10). The rms error affecting the simulated $G$ is rather large and the skill score (not shown) displays negative values for all the models, denoting an inconsistency of either the measurements or the models. Such errors may be explained by the influence of the mulch: the explicit simulations of the mulch effect by SiSPAT, in particular, shows that the presence of a mulch significantly modifies the surface energy balance by decreasing soil evaporation and soil temperature, and increasing soil surface water content. Another problem caused by the mulch is that in reality, the heat storage in the soil is conditioned by the mulch whereas the measured $G$ was obtained from heat flux plates buried at a $3-\mathrm{cm}$ depth in the soil. Although a correction was made to account for the effect of the $3-\mathrm{cm}$ soil top layer on $G$, the mulch effect could not be properly characterised, and the soil heat flux at the surface of the mulch could not be properly evaluated. It appears that the simulated $G$ (at the mulch surface) displays a much larger diurnal cycle than the measured one. This affects the estimation of the latent heat flux, which was derived from the surface energy budget. On the other hand, the mean bias over $G$ is very small with SiSPAT (Table 4) and the cumulated flux is simulated well (Fig. 9). The overestimation of $R n$ with ISBA and MAGRET (Table 4) is consistent with the overestimation of $H$ and suggests that the modelled surface temperature is underestimated (because more energy is removed from the surface through the heat flux in the model). The reverse conclusion can be drawn from the results of ALiBi, which uses the observed bulk temperature $T_{I R}$ to estimate the fluxes (both $R n$ and $H$ are underestimated), suggesting that the three models
Table 4. Errors affecting the simulated half-hourly outputs of ISBA, MAGRET, ALiBi, and SiSPAT in terms of rms error, mean bias (simulated minus observed), and model skill score on: evapotranspiration $(L E)$, heat flux $(H)$, net radiation $(R n)$, soil heat flux $(G)$, surface temperature $\left(T_{s}\right)$, and soil water storage $\left(w_{2} \times d_{2}\right)$. Note that ALiBi's simulation only covers some periods and that ISBA's scores for the ALiBi's periods are shown in parenthesis

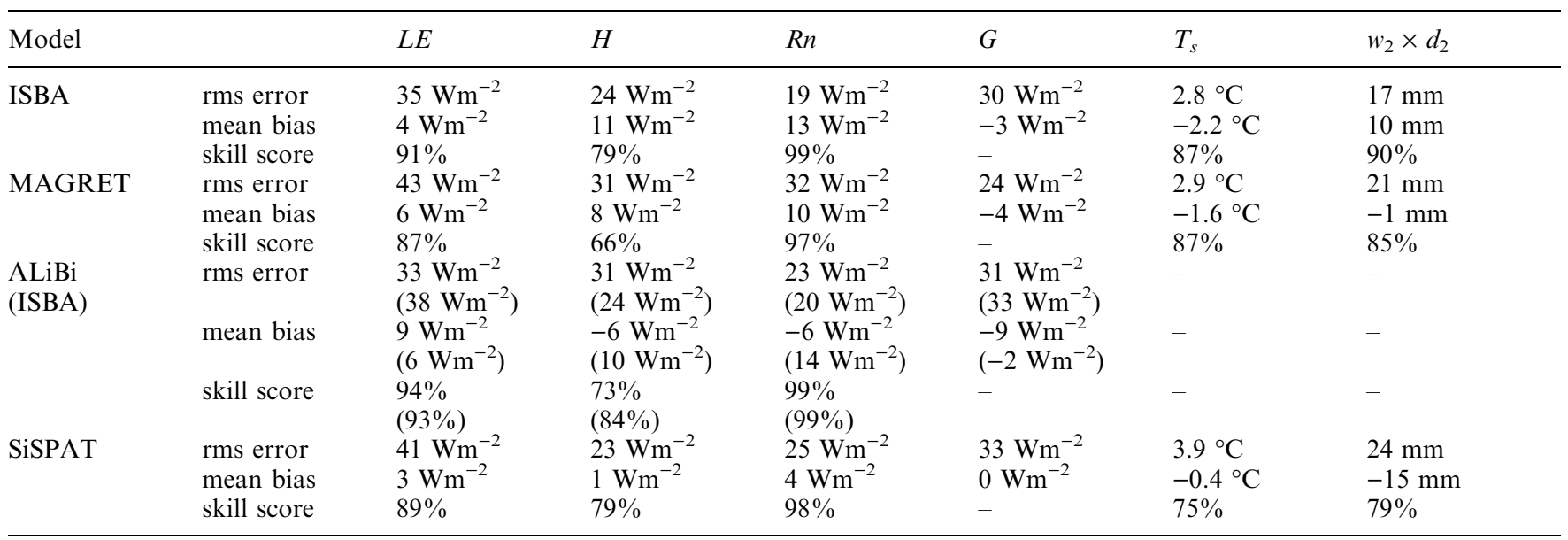



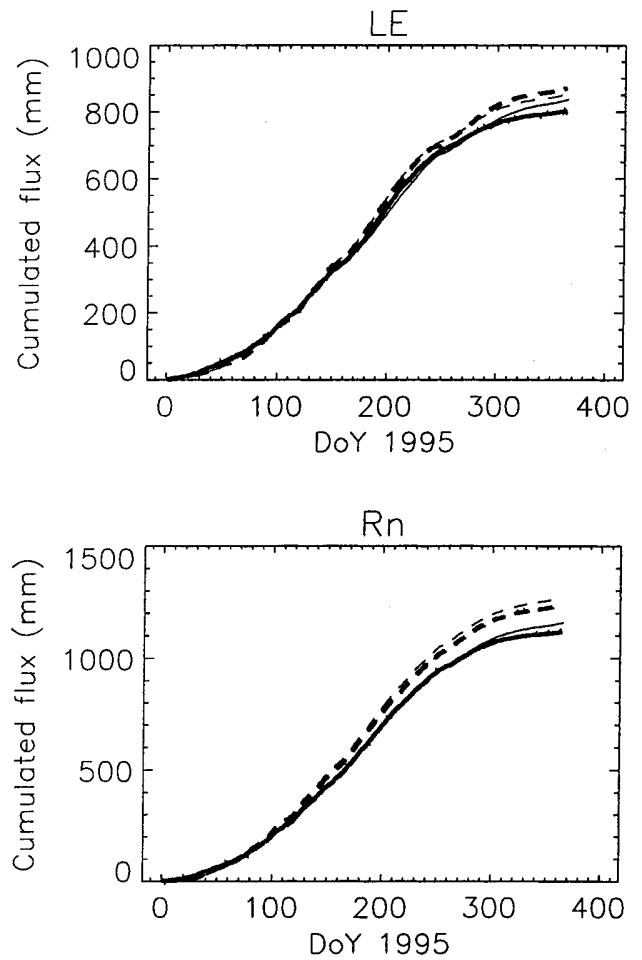
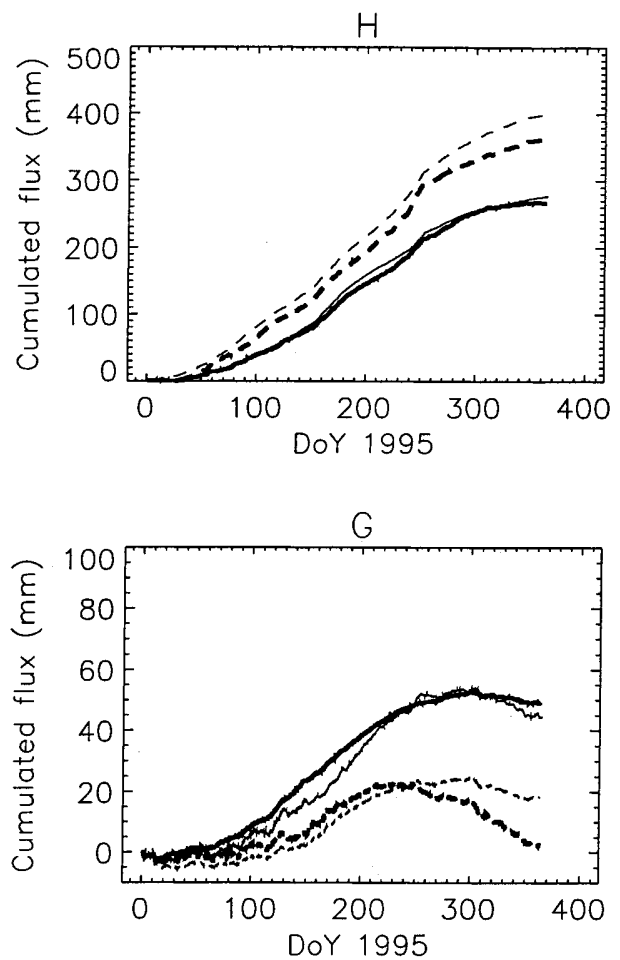

Fig. 9. Comparison between the simulated and measured cumulated fluxes of water vapour $(L E)$, heat $(H)$, net radiation $(R n)$, and heat storage in the soil and the biomass $(G)$ over 1995. The thick solid line represents the measured values. The simulations are represented by: fine solid line (SiSPAT), and dashed lines (fine dashes for ISBA, and thick dashes for MAGRET) have difficulties in accounting for the mulch effect. As far as the latent heat flux is concerned, both instantaneous and cumulated flux values are relatively well simulated by the models (the model skill score is about 90\% for all the models). After DoY 270 in 1995, all the models tend to overestimate evapotranspiration (Fig. 10). This may be caused, probably, by overestimated values of LAI during this period (Fig. 6), imposed on all the models. The high value of the observed cumulated evapotranspiration (Fig. 9) is well reproduced by ISBA, MAGRET, and SiSPAT, with a rather low minimum stomatal resistance: $r_{\text {smin }}=50 \mathrm{~s} \mathrm{~m}^{-1}$. It must be noted that this value is comparable with previous calibrations of ISBA over grasslands (Noilhan et al., 1993). It is interesting to note that high evapotranspiration rates are also obtained with ALiBi, based on surface temperature data only, without describing the soil water budget and the water excess.

\subsection{Surface temperature}

The errors on surface temperature are listed in Table 4. On average, the surface temperatures simulated by ISBA and MAGRET tend to be lower than the measured $T_{s}$. This is particularly true for ISBA, with a mean bias of $-2.2{ }^{\circ} \mathrm{C}$. This is consistent with the bias between the

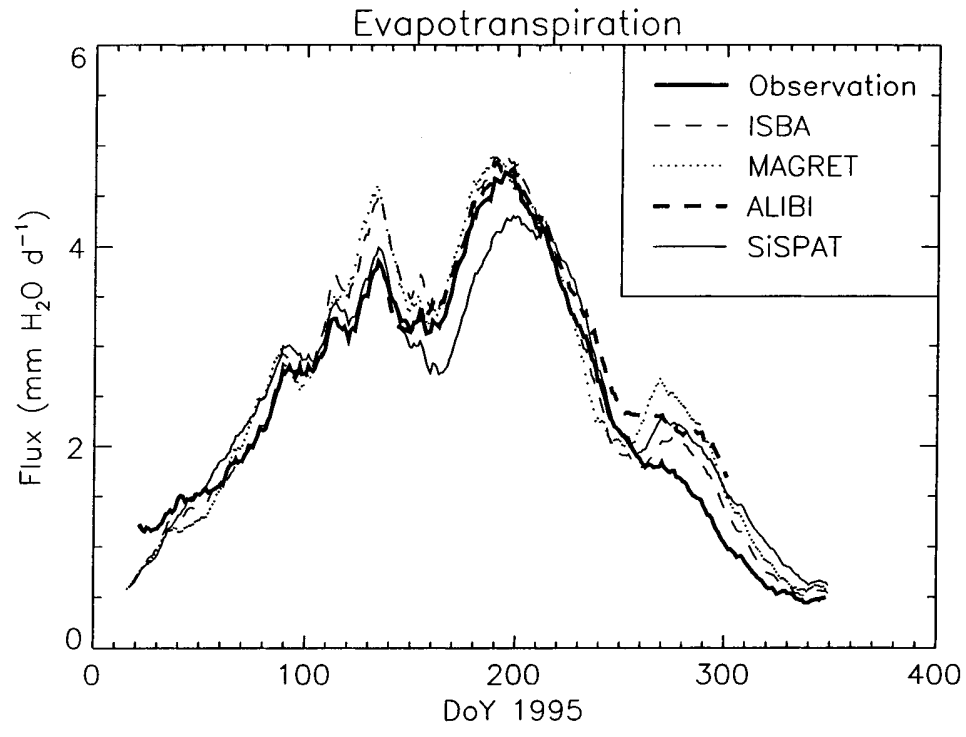

Fig. 10. The daily evapotranspiration as measured and modelled by ISBA, MAGRET, and ALiBi over 1995. The annual cycle is smoothed using a 30 -day moving average in order to show the general trend 
modelled and the observed $R n$ (Table 4). An explanation is that ISBA and MAGRET, being single energybudget models, tend to simulate a surface temperature which is representative of both vegetation and soil surface. On the other hand, the mean bias on $T_{s}$ given by SiSPAT is low, consistent, again, with the good representation of the cumulated fluxes by this model (Fig. 9). However, the SiSPAT skill score concerning $T_{s}$ is lower than the other models $(75 \%$, against $87 \%$ for ISBA and MAGRET). This is due to a systematic overestimation of daytime $T_{s}$ and underestimation of nighttime $T_{s}$ by SiSPAT.

\subsection{Soil moisture}

Figure 11 presents the values of the total soil water content simulated by ISBA, MAGRET, and SiSPAT. The agreement is relatively good, with a rms error of 17 and $21 \mathrm{~mm}$ for ISBA and MAGRET, respectively, and $24 \mathrm{~mm}$ for SiSPAT (Table 4). As shown in Fig. 11, the soil moisture simulated by ISBA may be higher than field capacity in wintertime. Although this is physically possible (soil moisture at saturation is higher than the field capacity equilibrium value), it condradicts the observations and may denote a problem in the parametrisation of infiltration and drainage. MAGRET and SiSPAT present lower soil moisture values during autumn. This latter feature corresponds to the negative soil water change obtained with these models in Table 2 . The problem with the simulation of the root soil moisture in ISBA (or MAGRET) is related to the difficulty of defining the root zone and the absence of a description of the amount of water either directly extracted by the roots or provided by the capillarity rises (Boone et al., 1999). The soil water stress function employed in the expression of stomatal resistance may also differ from reality in some cases. Finally, it is

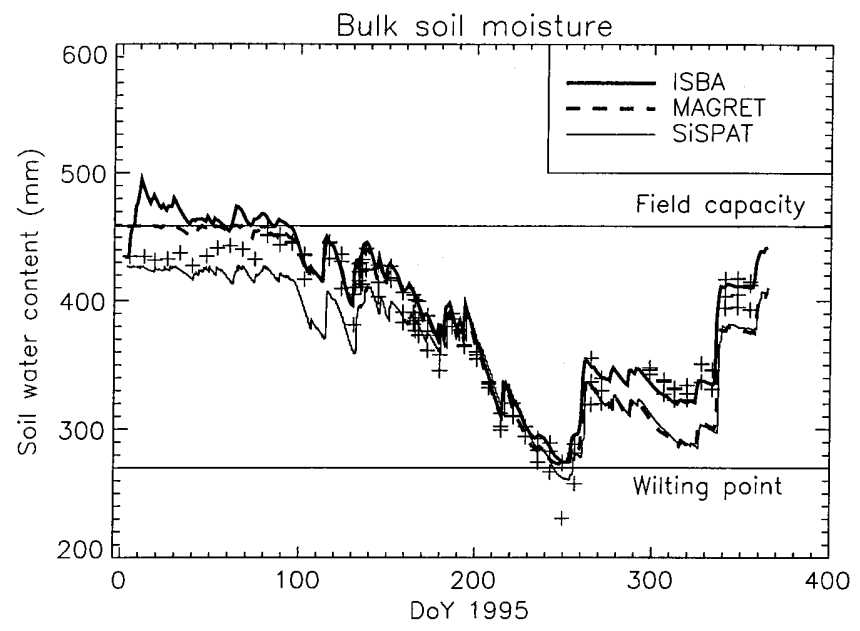

Fig. 11. The measured (pluses) and simulated (solid and dashed lines) soil water content of the $1.35 \mathrm{~m}$ soil column in 1995 . The measurements differ slightly from those presented in Calvet et al. (1998a) because the neutron probe output calibration was refined, and all the measured sites are presented impossible to account for texture gradients in simple models like ISBA and MAGRET. In spite of these difficulties, ISBA seems to be the best model of soil moisture for this dataset, with a skill score of $90 \%$. One factor that may explain the poor performance of SiSPAT (skill score of $79 \%$ ) is the large amount of surface runoff generated by the model, at the expense of drainage (Table 2).

As far as surface soil moisture is concerned, a comparison of the surface soil moisture $w_{g}$ simulated by ISBA with the measured values was carried out by Calvet et al. (1998a). It was shown that the ISBA $w_{g}$ outputs compare well with the measurements corresponding to a value integrated over the soil top $5-\mathrm{cm}$ layer. Using SiSPAT, the observed high values of $w_{g}$ are better reproduced by explicitly modelling the transfers within the mulch (Gonzalez-Sosa et al., 1999).

\subsection{Net assimilation of carbon dioxide}

As $\mathrm{CO}_{2}$ net assimilation by the canopy $(A n)$ was not measured in 1995, only modelled annual cycles are presented in Fig. 12. Values of $A n$ are provided by $\mathrm{ALiBi}$, and also by the new version of ISBA computing photosynthesis (Calvet et al., 1998b): ISBA-Ags. The curve displayed in Fig. 12 concerning ISBA-Ags was obtained by imposing the same $L A I$ values as for the other models. Namely, ISBA-Ags was run in the configuration where photosynthesis and stomatal conductance are calculated as in Jacobs et al. (1996), without inferring plant growth. Both models give a realistic magnitude of net assimilation (based on the $\mathrm{CO}_{2}$-flux measurements of 1997 and 1998 presented in Sect. 4) and the general trend is the same. However, the $A n$ values given by ALiBi are $15 \%$ larger than the ISBAAgs ones, on average.

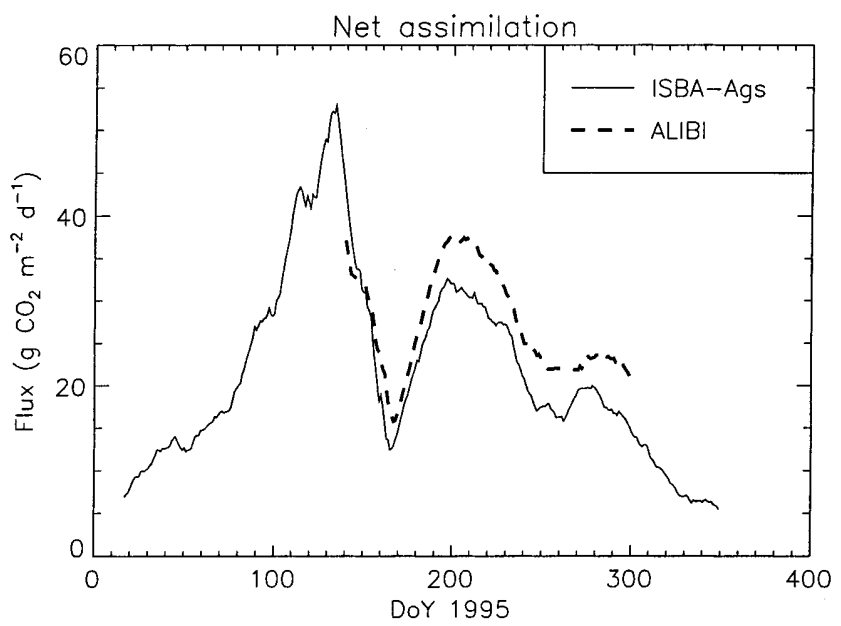

Fig. 12. The daily net $\mathrm{CO}_{2}$ assimilation as modelled by ISBA-Ags (Calvet et al., 1998b) and ALiBi in 1995. The annual cycle is smoothed using a 30-day moving average in order to show the general trend 


\section{Summary and conclusions}

The MUREX continuous micrometeorological and soil moisture observations of 1995, 1996, and 1997 are presented. The MUREX experiment provided a unique dataset comprising continuous atmospheric, vegetation and soil measurements over more than three years, over a fallow site. The observations showed that a different amount of water was extracted from the soil reservoir from one year to another, depending on the rainfall regime. Most often than not, the soil water supply (from either soil water storage or uphill water input) was large enough to permit values of evapotranspiration higher than the sensible heat flux. In spite of the buffer effect of the soil, the growing cycle of the fallow studied showed a clear dependence on the rainfall regime: the maximum $L A I$ varied between 2 and 3.5 according to the year considered. Data analysis and model results show that transfers of heat and water were influenced by the presence of a mulch in the vegetation layer. This led to difficulties especially in the estimation of the ground heat flux and consequently on the latent heat flux, derived as the residual of the energy budget. The existence of lateral transfers associated with a perched water table was also shown. However, the measurement uncertainties make their exact quantification difficult.

The data of 1995 were employed to assess the ability of the surface schemes ISBA, MAGRET, SiSPAT, and ALiBi to simulate properly the energy and water budgets of a vegetated surface over a complete annual cycle. The surface schemes describing soil moisture and the water balance (ISBA, MAGRET, and SiSPAT) were modified to include the contribution of lateral transfers to the water input. SiSPAT was also modified to explicitely model heat and water transfers within the mulch. Although this allowed a significant improvement of the model results, further studies are needed to better assess the influence of mulch parameters on the results. Data from 1996 and 1997 will be used to refine the mulch parameters and the occurrence of capillarity rises and lateral inflows.

All the models are able to reproduce the general trend of the measured variables. However, the surface temperature is significantly underestimated by ISBA and MAGRET. The $\mathrm{CO}_{2}$ net assimilation simulated by $\mathrm{ALiBi}$ is also significantly different from the ISBA-Ags results. It must be noted that any SVAT off-line simulation requires prescribed boundary conditions. Together with the observed atmospheric forcing and vegetation characteristics, such as $L A I$, the studied models (apart from ALiBi) use estimates of water excess $X$ s (Sect. 3.3) and deep soil temperature, obtained from the field measurements. Soil water excess, which results from lateral transfers, cannot be simulated by 1D SVATs and must be prescribed from observations. These ground boundary conditions are far from being major components controlling the seasonal evolution but need to be accounted for in order to simulate the observed energy and water budgets. Of course, a part of the model interseasonal to inter-annual variability is constrained by observations ( $L A I$, and the radiative and atmospheric forcing being the main factors). However, estimating the surface temperature and the water partitioning between vegetation transpiration, drainage, surface runoff, and soil moisture change is not easy, as shown in Sect. 7. It is expected that the MUREX data will be useful to test interactive vegetation SVAT models, in which photosynthesis is computed and may be employed to estimate the biomass production and LAI (Calvet et al., 1998b).

Primarily, the aim of MUREX is to provide continuous micrometeorological and soil moisture observations during several years, in order to assess the ability of simple surface schemes employed in meteorology to simulate properly the energy and water budgets of the surface. Such a dataset could be useful to complete the on-going intercomparison PILPS program (Chen et al., 1997). In particular, the PILPS program has shown that different parametrisations of soil water and runoff can cause a very large variability in the simulated root-zone soil moisture. Also, the functional relationship between the parametrisation of the root-zone soil moisture and the evapotranspiration vary from one model to another (Mahfouf et al., 1996).

It is likely that such a dataset will also be employed to analyse the model shortcomings and to propose new parametrisations. Moreover, the MUREX dataset may be useful to test assimilation techniques. For example, Calvet et al. (1998a), using the measurements of surface soil moisture and surface temperature, have proposed assimilation rules of these variables to retrieve the rootzone soil water content.

Acknowledgements. This work was funded by the Conseil Régional de Midi-Pyrénées, the Programme National de Recherche en Hydrologie, and by participants to the field programme (MétéoFrance/CNRM, CESBIO, LTHE).

Topical Editor J.-P. Duvel thanks Yongkang Xue and another referee for their help in evaluating this paper.

\section{References}

André, J.-C., J.-P. Goutorbe, and A. Perrier, HAPEX-MOBILHY: a hydrologic atmospheric experiment for the study of water budget and evaporation flux at the climate scale, Bull. Am. Meteorol. Soc., 67(2), 138-144, 1986.

Bessemoulin, P., J.-C. Calvet, G. Jaubert, J. Noilhan, D. Vignes, C. Tosca, I. Braud, R. Haverkamp, J.-L. Thony, and M. Vauclin, MUREX : Un programme de suivi du cycle annuel des échanges de masse et d'énergie entre sol, végétation, et atmosphère. Premiers enseignements, in Atelier Expérimentation et Instrumentation, Météo-France/CNRM, October 1996, Toulouse, pp. 289-294, 1996.

Bolle, H. J., J.-C. André, J.-L. Arrue, H. K. Barth, P. Bessemoulin, et al., EFEDA: European field experiment in a desertificationthreatened area, Ann. Geophysicae, 11, 173-189, 1993.

Boone, A., J.-C. Calvet, and J. Noilhan, Inclusion of a third soil layer in a land-surface scheme using the force-restore method, J. Appl. Meteorol., in press, 1999.

Braud, I., A. C. Dantas-Antonio, M. Vauclin, J.-L. Thony, and P. Ruelle, A simple soil-plant-atmosphere transfer model (SiSPAT): development and field verification, J. Hydrol., 166, 213-250, 1995. 
Brooks, R. H., and A. T. Corey, Hydraulic properties of porous media, Colo. State Univ. Fort Collins Hydrol. Pap., 3, 1964.

Brutsaert, W., Evaporation into the atmosphere, D. Reidel, Dordrecht, 299 pp, 1982.

Calvet, J.-C., J. Noilhan, and P. Bessemoulin, Retrieving the rootzone soil moisture from surface soil moisture or temperature estimates: A feasibility study based on field measurements. J. Appl. Meteorol., 37(4), 371-386, 1998a.

Calvet, J.-C., J. Noilhan, J.-L. Roujean, P. Bessemoulin, M. Cabelguenne, et al., An interactive vegetation SVAT model tested against data from six contrasting sites, Agric. For. Meteorol., 92, 73-95, 1998b.

Chen, T. H., A. Henderson-Sellers, P. C. D. Milly, A. J. Pitman, A. C. M. Beljaars, et al., Cabauw experimental results from the project for intercomparison of landsurface parametrisation schemes (PILPS), J. Clim. 10, 1194-1215, 1997.

Courault, D., J.-P. Lagouarde, and B. Aloui, Evaporation for maritime catchment combining a meteorological model with vegetation information and airborne surface temperatures, Agric. For. Meteorol., 82, 93-117, 1996.

Daget, P., and J. Poissonet, Une méthode d'analyse phytologique des prairies. Critères d'application. Ann. Agronom., 22, 5-41, 1971.

Deardorff, J. W., A parametrisation of the ground surface moisture content for use in atmosphere predictions models, J. Appl. Meteorol., 16, 1182-1185, 1977.

Deardorff, J. W., Efficient prediction of ground temperature and moisture with inclusion of a layer of vegetation, J. Geophys. Res., 83, 1889-1903, 1978.

Elrick, D. E., and W. D. Reynolds, Methods for analysing constanthead well permeameter data, Soil Sci. Soc. Am. J., 56(1), 320323, 1992.

Goutorbe, J.-P., A critical assessment of the Samer network accuracy, In Eds T. J. Schmugge, and J. -C. André Land surface evaporation. Measurement and parametrisation, Springer-Verlag, Berlin Heidelberg, New York, pp. 171-182, 1991.

Goutorbe, J.-P., T. Lebel, A. J. Dolman, J. H. C. Gash, P. Kabat, et al., An overview of HAPEX-Sahel: a study in climate and desertification, J. Hydrol., 188-189, 4-17, 1997.

Jacobs, C. M. J., B. J. J. M. van den Hurk, and H. A. R. de Bruin, Stomatal behaviour and photosynthetic rate of unstressed grapevines in semi-arid conditions, Agric. For. Meteorol., 80, 111-134, 1996

Jacquart, C., and E. Choisnel, Un modèle de bilan hydrique simplifié à deux réservoirs utilisable en agrométéorologie, $L a$ Météorol., 8(9), 29-43, 1995.

Koster, R. D., and P. C. D. Milly, The interplay between transpiration and runoff formulations in land surface schemes used with atmospheric models, J. Clim., 10(7), 1578-1591, 1997.

Lagouarde, J.-P., Use of NOAA-AVHRR data combined with an agrometeorological model for evaporation mapping, Int. J. Remote Sens., 12(9), 1853-1864, 1991.

Laurent, J.-P., Evaluation des paramètres thermiques d'un milieu poreux: optimisation d'outils de mesure 'in situ', Int. J. Heat Mass Trans., 32(7), 1247-1259, 1989.
Mahfouf, J.-F., A. O. Manzi, J. Noilhan, H. Giordani, and M. Déqué, The land surface scheme ISBA within the Météo-France climate model ARPEGE. Part I: implementation and preliminary results, J. Clim., 8(8), 2039-2057, 1995.

Mahfouf, J.-F., C. Ciret, A. Ducharne, P. Irannejad, J. Noilhan, et al., Analysis of transpiration results from the RICE and PILPS workshop. Global Planet. Change, 13, 73-88, 1996.

Noilhan, J., and S. Planton, A simple parametrisation of land surface processes for meteorological models, Mon. Weather Rev., 117, 536-549, 1989.

Noilhan, J., and J.-F., Mahfouf, The ISBA land surface parametrisation scheme. Global Planet. Change, 13, 145-159, 1996.

Noilhan, J., J.-F. Mahfouf, A. Manzi, and S. Planton, Validation of land-surface parametrisations: developments and experiments at the French weather service, in Validation of models over Europe (2), ECMWF seminar proceedings, Reading [7-11 September 1992] pp. 125-158, 1993.

Olioso, A., Simulation des échanges d'énergie et de masse d'un couvert végétal, dans le but de relier la transpiration et la photosynthèse aux mesures de réflectance et de température de surface. PhD Thesis, University of Montpellier, France, 1992.

Olioso, A., T. Carlson, and N. Brisson, Simulation of diurnal transpiration and photosynthesis of a water stressed soybean crop, Agric. For. Meteorol., 81, 41-59, 1996a.

Olioso, A., O. Taconet, and M. Ben Mehrez, Estimation of heat and mass fluxes from IR brightness temperature, IEEE Trans. Geosci. Remote Sensing, 34, 1184-1190, 1996b.

Sellers, P., F. G. Hall, G. Asrar, D. E. Strebel, and R. E. Murphy, An overview of the First International Satellite Land Surface Climatology Project (ISLSCP) Field Experiment (FIFE), $J$. Geophys. Res., 97(D17), 18 345-18 371, 1992.

Shuttleworth, W. J., and J. S. Wallace, Evaporation from space crops - an energy combination theory, Q. J. R. Meteorol. Soc., 111, 839-855, 1985.

Staley, D. O., and G. M. Jurica, Effective atmospheric emissivity under clear skies, J. Appl. Meteorol., 11, 349-356, 1972.

Troufleau, D., J. P. Lhomme, B. Monteny, and A. Vidal, Sensible heat flux and radiometric surface temperature over sparse Sahelian vegetation. I. An experimental analysis of the $\mathrm{kB}^{-1}$ parameter, J. Hydrol., 188-189, 815-838, 1997.

Vachaud, G., A. Passerat de Silans, P. Balabanis, and M. Vauclin, Temporal stability of spatially measured soil water probability density function, Soil Sci. Soc. Am. J., 49(4), 822-828, 1985.

Van Genuchten, M. T., A closed-form equation for predicting the hydraulic conductivity of unsaturated soils, Soil Sci. Soc. Am. J., 44, 892-899, 1980.

Vauclin, M., and J.-L. Chopart, L'infiltration multi-disques pour la détermination in situ des caractéristiques hydrodynamics de la surface d'un sol gravillonaire de la Côte d'Ivoire, Agron. Trop., 46, 259-271, 1992.

Verhoef, A., H. A. R. de Bruin, and B. J. J. M. Van den Hurk, Some practical notes on the parameter $\mathrm{kB}^{-1}$ for sparse vegetation, J. Appl. Meteorol., 36(5), 560-572, 1997.

Winkel, T., and S. Rambal, Stomatal conductance of some grapevines growing in the field under a mediterranean environment, Agric. For. Meteorol., 51, 107-122, 1990. 